\title{
An initial categorization of foundational research in complex technical systems
}

\author{
Imre HORVÁTH \\ (Faculty of Industrial Design Engineering, Delft University of Technology, 2628 CE Delft, the Netherlands) \\ E-mail: i.horvath@tudelft.nl \\ Received June 8, 2015; Revision accepted Aug. 4, 2015; Crosschecked Aug. 6, 2015
}

\begin{abstract}
There has been intense foundational research in complex technical systems (CTSs) over the last half century. These systems are exemplified by advanced mechatronics systems, embedded control systems, real-time systems, agent-based smart systems, distributed software systems, internet of things systems, and cyber-physical systems. The objective of this paper is to offer an initial cataloguing of the various research domains and to identify the major research issues. The paper has an ontological flavour, because it concentrates on what research has been and is being done, rather than on why and how research is done. The underpinning study has been done in three stages: (i) intuition-driven exploration of a reference set of related academic publications, (ii) evidence-based specification of a categorization of the domains and subdomains of research, and (iii) refinement and validation of the proposed classification based on a control set of related academic publications. The proposed reasoning model identifies three categories of research domains. The 'intellectualizations' category includes research domains such as: (i) philosophy, (ii) ontology, and (iii) epistemology of CTSs. The research domains included in the 'realizations' category are: (iv) methodology, and (v) creation of CTSs. The domains considered in the 'influences' category are: (vi) manifestations, and (vii) axiology of CTSs. Based on the proposed reasoning model a landscape of foundational research in CTSs is proposed for public debate. Our follow-up study focuses on the extension of the proposed classification to other families of complex engineered systems such as sociotechnical systems and social ecosystems.
\end{abstract}

Key words: Foundational research, Complex technical systems, Initial categorization, Research categories and domains doi:10.1631/jzus.A1500172 Document code: A CLC number: TP302

\section{Introduction}

Everything is a system, even a system of systems. Huge or tiny, it does not really matter. Regarding something as a system depends only on our perspective. Possibly, this is the most important recognition of our post-industrial age (Cabrera et al., 2008). This recognition has triggered an immense amount of research into systems (Muller, 2013). As early as the beginning of the 1970s, Ackoff (1974) analysed the system revolution. In the last five decades, systems science has gone through its formation phase and it exists today as a flourishing domain of knowing and

(D) ORCID: Imre HORVÁTH, http://orcid.org/0000-0002-6008-0570 (c) Zhejiang University and Springer-Verlag Berlin Heidelberg 2015 doing. Starting with the pioneering work of (von Bertalanffy, 1950a), systems science abandoned the reductionist worldview of classical natural, human and technical sciences, and introduced a holistic view in the investigations of completely dissimilar biologic, ecologic, cybernetic, symbolic, technical, and social systems. As the literature shows, the landscape of research in complex engineered systems has become almost incomprehensibly broad and heterogeneous (both curiosity and problem driven). But the literature also shows that it has hardly been investigated from a taxonomical viewpoint (i.e., with the intent of classifying the various fields of interest and the different research approaches in a comprehensive manner). Some efforts with specific focus and purpose have nevertheless been made. For example, 
research on classification of intelligent robot architectures was reviewed by Liu et al. (2003). The objective of this paper is to support and contribute to the advancement of such work.

What is offered in this paper is an initial cataloguing of the various research domains, together with the identification and concise discussion of the major research concerns within each domain. However, we concentrate only on what kinds of foundational research have been and are being done, rather than on why and how research is done. Therefore, the paper has an ontological flavour. The term 'foundational research' is used here to refer to all activities that are done with the aim of grounding the intelligence of system science. Foundational research intends to create generic (investigator and context independent) testified disciplinary knowledge. It is expected that, after necessary public debate and consolidation, the proposed classification of the foundational research domains can contribute to the meta-knowledge of complex engineered systems.

Our background research has been done in three stages: (i) intuition-driven exploration of a reference set of related academic publications, (ii) evidencebased specification of a categorization of the domains and subdomains of research, and (iii) refinement and validation of the proposed classification based on a control set of related academic publications. In the first stage, a keyword-based literature search was completed using intuitively selected keywords such as 'complex systems', 'system science', 'engineered systems', and 'system development'. As the explorative search progressed, more and more related notions, terms, and concepts popped up, based on which additional keywords were formulated and used in the search. During the last two years, more than $860 \mathrm{ac}-$ ademic publications (articles, papers, and research reports) were identified as relevant for forming a reasoning model. In the first stage of the work, the collected publications were sorted, in an arbitrary manner, into two approximately equal sets, which are referred to as reference set and control set. In the second stage, the publications in the reference set were used as evidence that a particular research interest does exist, and a research subdomain was specified when multiple academic publications addressing the same research challenge or issue were found. The subdomains were allocated to research domains based on critical analysis, and the research domains were sorted into three abstract categories, which formed the backbone of the proposed classification. In the third stage, the control set of academic publications was used to validate the derived taxonomy and to introduce refinements and reinterpretations whenever it seemed to be necessary.

This undertaking was rather challenging due to the extremely large number and versatility of relevant books, articles, papers, reports, and other communications. A second challenge was raised by the total number of pages available in this paper for reporting on our work and results. The bottom-line criterion for including a particular publication in our study was if it contributed to foundational research. The 'proper' publications have been sorted based on the following four factors: (i) measure of topical compliance (relevance or congruence) of the publication to a conceptualized research domain: $0<\alpha<1$, (ii) proportion contributing to a given domain if the publication happens to contribute to multiple domains: $0<\lambda_{x}<1$, (iii) measure of the relative significance of the publication based on existing citations, $c=C /\left(C+C_{\mathrm{s}}\right)$, where $c$ is the citation factor, $C$ is the total number of existing citations of a publication at the time of the study $(C>1)$, and $C_{\mathrm{s}}$ is the minimum number of independent citations of a publication to be considered as seminal $\left(C_{\mathrm{s}}=100\right.$, by informed subjective choice), and (iv) the relative visibility factor, $\tau=\left(Y_{\mathrm{r}}-Y_{\mathrm{p}}\right) / Y_{\mathrm{r}}$, where $Y_{\mathrm{p}}$ is the year of the first appearance of the considered publication, and $Y_{\mathrm{r}}$ is the year of conducting our study (where $Y_{\mathrm{r}}=2014$ ). Based on these measures a nonlinear domain compliance indicator, DCI $=\left(\alpha \lambda_{x} c\right) / \tau$ was generated and used for selecting and sorting the publications.

Instead of any known co-publication (Aberer and Hauswirth, 2001) and citation networks analysis (Chen, 1999) and emerging research front detection methods (Shibata et al., 2008), this methodological approach was used for clustering because the author hypothesized a particular cognitive framework in advance and it was taken as a starting point for processing the related literature. After briefly addressing definitional issues and referring to important previous work, the content of the proposed reasoning model will be discussed in the next section. In the rest of the paper, the identified subdomains will be discussed briefly and some demonstrative publications will be cited. 


\section{Towards a comprehensive reasoning model}

Thinking about the current state of foundational research in complex technical systems (CTSs) and making efforts to map it according to a formal framework model are useful for at least three reasons. First, though there are many monographs, papers, and reports published on systems thinking and systems science, the various branches and approaches of research are not thematically processed and grouped. Second, though ideas/concepts about systems and their characteristics are published in the related literature, knowledge concerning foundational research approaches and methodologies is not shared. Third, the notion of systems is in motion-more and more specific complex systems are considered in rational investigations and in empirical studies. This assumes an up-to-date awareness of the latest findings of each active member of the research community. Putting more emphasis on ontological studies of systems research will support the resolution of the above issues.

Previous work focused more on knowing systems, rather on knowing systems research, and argued about a wider spectrum of systems. They were driven by: (i) the topographic models of systems science proposed in the past, (ii) the range of systems considered, or (iii) the nature of engineering research (Ta'eed, 1986). For instance, it was proposed by Wilber (2001) to classify system subdomains as: (i) interior subjective systems (including individual and collective systems), and (ii) exterior objective systems (including individual and collective systems). The psychological evolution driven subjective, psychological, thought systems are considered individual intersubjective systems, and the behavioural evolution driven natural and/or designed systems as interobjective systems. The cultural evolution driven ideological, religious, and axiological systems are regarded as collective intersubjective systems, and the social evolution driven social, sociotechnical, and/or human activity systems are collective interobjective systems.

Several efforts have been made to develop conceptual maps of system science; however, these do not explicitly address the research approaches. For instance, Badillo-Piña et al. (2011) proposed a pattern for the structure of systems science as a whole: (i) domain of relevance (consciosphere, biosphere, physiosphere), (ii) concepts $\quad=>$ epistemology (conceptual space, thoughts, and language), (iii) philosophy $\Leftrightarrow>$ theory (theoretical relations), and (iv) methodology $<=>$ applications (methods of investigations and problem solving). Based on much previous work, they identified four hierarchical levels where systems are manifest: (i) the realm of matter (organizational levels of physical and physiochemical systems), (ii) the realm of life (organizational levels of biological systems), (iii) the realm of society (organizational levels of socioeconomic systems), and (iv) the realm of consciousness (organizational levels of psycho-cultural systems), which represent increasing coherence and complexity, and decreasing relative abundance of systems. One generally accepted opinion has been that system science is holistic, while natural science is reductionist, but eventually scientifically-based holism also assumes determinism and objective knowledge.

Based on aspects of investigation of the philosophy of science and on findings from studying the reference set of publications, the preliminary reasoning model shown in Fig. 1 has been constructed. For the sake of clarity we note that it was not at all our objective to provide a new taxonomy of complex systems, or to propose a new classification of the disciplinary domains pertaining to systems science. We pursued mapping the whole area of foundational research in CTSs onto this model, while guaranteeing logical order and content-wise coherence of the identified subdomains. Openness of the proposed classification was of importance, since there has also been broadly-based research in other families of complex systems, such as socio-technical systems (Kroes et al., 2006).

The proposed reasoning model identifies three categories of research domain. The 'intellectualizations' category includes those research domains, such as: (i) philosophy, (ii) ontology, and (iii) epistemology of systems, which use speculative, rational or empirical reasoning or observations to explore and consolidate the fundamentals and generic characteristics of CTSs. The research domains included in the 'realizations' category are: (iv) methodology, and (v) creation of CTSs. These investigate the generic concepts, approaches, constituents, characteristics, and means of bringing CTSs into existence. The 
domains considered in the 'influences' category are: (vi) manifestations, and (vii) axiology of CTSs, which are focusing on the embedding of systems in society, the values implied and created by systems, and the various forms of their impacts (Hoschka, 1996). In the following sections, we explore these categories and identify the most important related subdomains.

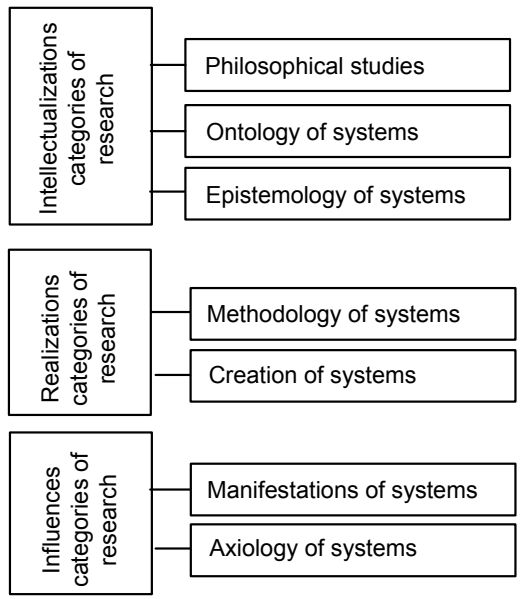

Fig. 1 Preliminary reasoning model

\section{Philosophical studies of systems}

Many alternative philosophies have been proposed to reveal the essence of generic systems, complex systems, and complex engineered systems. The studies by system philosophers typically follow a speculative rational way towards new theories and facts, rather than an empirical way. The proposed subdomains of philosophical studies of complex systems are shown in Fig. 2.

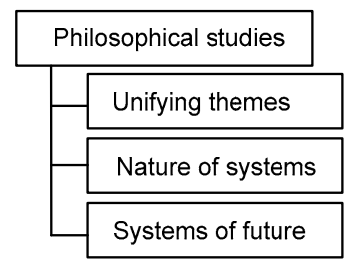

Fig. 2 Subdomains of philosophical studies related to CTSs

\subsection{Unifying themes}

Philosophical studies deal with many unifying themes of systems, such as holism, complexity, emergence, intelligence, adaptability, autonomy, organization, evolution, dynamics, resilience, models, etc. (Kirschenmann, 1984). To express the idea that there is a tendency of the whole to be greater than the sum of its parts in the case of engineered systems, the word holism was introduced by Smuts (1926). Complexity is generally used to characterize systems with many parts interacting with each other in multiple, often non-deterministic ways. In systems science, the concept of complexity expresses that the attributes of system-hood are nonlinear, i.e., depend on interactions and involve multiple feedback loops, while their structures, patterns, and processes remain coherent (Ulrich, 1988). Complex systems are investigated as multi-component and multi-relation arrangements that cannot be accounted for completely in terms of the properties of the components (Flood and Carson, 1993). The notion of complexity was projected to distributed systems and metrics for measuring various aspects of complexity (considering both intrinsic complexity of a system and the complexity of using a system to perform tasks) were proposed by Ranganathan and Campbell (2007).

Complicatedness is understood as the degree to which a decision unit of the system is able to manage the level of complexity presented by the system. The single most important fundamental characteristic shared by all complex systems is self-organization, which is a spontaneous appearance of large-scale organization through limited interactions among simple components, according to (Mina et al., 2006). Self-organization is a typical capability of natural systems, but current CTSs are also equipped with this capability, or with those means that enable them to obtain this capability (Grabowski, 2013). Emergence of large-scale order is seen as a process. Self-organization leads to the general capability of (machine) learning, which is also investigated as a specific form of inquiry done by CTSs (Eze et al., 2011).

\subsection{Nature of systems}

Research into the nature of systems typically uses system paradigms as indicators. A system paradigm is an abstract representation of a system, which intends to capture all distinguishable architectural, operational, materialization, implementation, utilization, etc., features. It also carries the set of fundamental assumptions of and the knowledge possessed 
by the concerned professional community about systems, as subjects of systematic investigations. System paradigms have also been addressed as metatheoretical assumptions about the nature and manifestations of systems. For instance, based on the social paradigms discussed by Burrell and Morgan (1979), Hirschheim and Klein (1989) considered four abstract paradigms: (i) functionalism (objectiveorder), (ii) social relativism (subjective-order), (iii) radical structuralism (objective-conflict), and (iv) neohumanism (subjective-conflict), for describing the nature of systems and analysed their influence on the development of information systems. Bi (2011) dealt with system paradigms in the context of sustainability of manufacturing systems. As a result of technological, industrial, social, and cultural developments, the nature of engineered systems is changing. This process is usually referred to as the shifting of system paradigms. Paradigmatic system features have been considered as indicators of the manifestation of system paradigms. These conceptual constructs, which describe genotypes, were proposed to describe and investigate CTSs, while 'manifestation system features' were introduced to describe phenotypes (Horváth and Pourtalebi, 2015).

\subsection{Systems of the future}

Rather than remaining exceptions, increasingly dynamic and disruptive change processes are becoming standard in the process of technological and social developments. Although millions of examples could be mentioned, let us refer to the elimination of the mechanical linkage between input devices and the operational device, such as brake pedals, steering wheel, and clutch pedals by introducing actuators realizing actions 'by-wire' in vehicles. Work looking into the future of systems conceptualized a road map in which the systems will have properties such as: (i) no central control or coordination, (ii) global behaviour emerging from local interactions of peers that are autonomous, (iii) being autonomous in decision making even on a component level, (iv) having the capability of non-designed-in adaptation, (v) benefiting from the possibility of self-reproduction, and (vi) interaction with stakeholders on semantic, pragmatic, and apobetic level (Thurman and Mitchell, 1994).

Computer systems based on the notion of the computer as assistant have recently become the focus of intense interest. The expanding role of the computer in everyday life and the growing number of 'relatively untrained' users make it necessary to think about new ways of dividing labour between humans and machines (West et al., 2000). Future systems must take on more tasks and perform them more competently and autonomously than existing systems, but if they are to be adequately flexible and responsive to complexity, they cannot automate their performance completely. Interestingly, the forecasts made a few decades ago can now be checked for their predictive power and correctness (Flood, 1989). It is reflected in the literature that due to rapid evolution, all aspects cannot be taken into account and thus long term forecasts are more uncertain and less reliable (Troncale, 2009).

\section{Research in systems ontology}

The general objective of this domain of research is to obtain new knowledge about the ontological nature of complex engineered systems and to derive semantic reference frameworks by imposing order on the area populated by ontological concepts. The subdomains of research in systems ontology of CTSs are shown in Fig. 3.

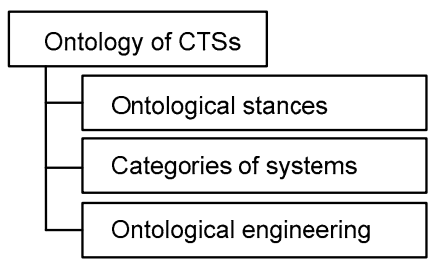

Fig. 3 Subdomains of research in ontologies of CTSs

\subsection{Ontological stances}

An ontological stance is understood as a philosophically informed view about reality-in our context, about the nature, existence, and knowledge of systems, and as such, is foundational for research (Hooker, 2011). Practically all ontological concerns are derived from certain ontological stances. This involves both characterization and classification. As an example, Bunge (1977) described three approaches to investigating the nature of systems: (i) atomistic, (ii) holistic, and (iii) systemic. For 
developments in systems philosophies, a more comprehensive classification was proposed by Bahm (1981). His types of system philosophy include: (i) atomism, (ii) holism, (iii) emergentism, (iv) structuralism, and (v) organicism. In his interpretation, for atomism, "particles exist without holes"; for holism, "the whole exists without parts"; for emergentism, "parts exist prior to wholes"; for structuralism, "wholes exist prior to parts"; and for organicism, "wholes and parts exist interdependingly". This is in line with the thoughts of Ackoff (1994), who differentiated three types of system: (i) mechanical, (ii) organismic, and (iii) social systems and argued that evolution of systems is progressing from mechanical through organismic to social. This is important since if we look at the historical development of CTSs, then we can observe the tendency of evolving from mechanical to socialized and personalized systems.

\subsection{Categories of systems}

A system "is any portion of the known universe (objective and subjective) that is selected mentally as separated from the rest of the universe, with the purpose of considering the different changes that can happen inside this portion of the universe under different conditions, organizations, structure, processes, and environments", in the interpretation of (Warfield, 2003). A hierarchy of epistemological types of system: (i) level 0: source system, (ii) level 1: data system, (iii) level 2: generative system, (iv) level 3: structure system, (v) level 4: metasystem, and (vi) level 5: meta-metasystem, was proposed by Klir (1985). He argued that systems on higher epistemological levels are distinguishable by the level of knowledge of the variables of the associated source system, and that it is possible to capture phenomena that involve change, such as adaptation, selforganization, evolution, etc., only at the metasystem level.

From a cybernetic point of view, every system reduces the entropy by creating some form of spatiotemporal order (Mayne, 1998). In the case of the first-level cybernetic systems, the triplet of informing-communication-control is the means of achieving this, while in the case of the second-level cybernetic systems it is triggered by the triplet of synergy-learning-adaptation, and for the third-order cybernetic systems it is holism-emergence-evolution.
One example of system manifestation-driven categorization (i.e., based on the type of the systems) is the one which distinguishes: (i) hard systems, (ii) quasihard systems, (iii) mixed systems, (iv) quasi-soft systems, and (v) soft systems. Based on the type of complexity involved, complex systems have been classified as: (i) compositionally, (ii) structurally, (iii) behaviourally, and (iv) dynamically complex systems. Many specific taxonomies of systems have been initiated, for instance for complex network systems and multi-agent systems (Bird, 1993).

\subsection{Ontological engineering}

Systems engineering ontologies (SEOs) are results of ontological engineering and said to be the means, on the one hand, of understanding the broad and multi-faceted nature of the systems engineering discipline (Sarder and Ferreira, 2007), and, on the other hand, of supporting quasi-semantic interoperability and cooperation of systems. SEOs are required to facilitate the integration of the formal and tacit knowledge of multiple disciplines and specialty groups (Mendes and Abran, 2005), and to assist interested parties in understanding the broad and multifaceted nature of the discipline of systems engineering (Li et al., 2008). Engineering ontologies have been defined as explicit representations of domain concepts and conceptualizations (Borst et al., 1997), facilitating information retrieval, knowledge filtering, and structuring (Chandrasekaran et al., 1999). Organization (logical and semantic structuring) of ontologies is a central issue (Wimsatt, 1994). Ontologies of software and components are an issue of current importance (Wongthongtham et al., 2009).

Engineering ontology models describe: (i) the objects and events (entities) in a domain of interest, (ii) the relationships between objects and events, (iii) the use of objects and events inside and outside the boundary of the domain, and (iv) the rules that govern the existence and behaviour of entities. Sarder and Ferreira (2007) proposed that a top level engineering ontology can be developed by including: (i) systems engineering (SE) objects (actors, such as individuals, teams, tools, and equipment, and products, such as artefacts, documents, and information), (ii) SE functions (technical management, such as project planning, project control, risk management, resource management), and (iii) process execution (i.e., 
mission analysis, requirements engineering, system architecting, system design, component integration, verification, and validation). Various methodologies have been proposed to support engineering ontology development (Li et al., 2009). It is also targeted to transform ontology development into a structured and comprehensive development process based on coordinated multi-disciplinary team efforts (Sicilia, 2007). The contents of domain ontologies, inclusion and association of ontologies, and validation of ontologies are other recognizable branches of current research.

\section{Research in systems epistemology}

As part of the philosophical theory of knowledge, systems epistemology is concerned with: (i) what knowledge CTSs are based on, (ii) what we know about them, (iii) what knowledge their implementation needs, and (iv) what knowledge they can possess and produce. Subdomains of research in epistemology of CTSs are shown in Fig. 4.

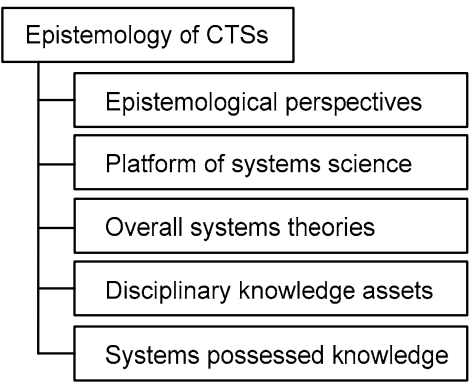

Fig. 4 Subdomains of research in epistemologies of CTSs

\subsection{Epistemological perspectives}

As an epistemological framework for dealing with systems, Ossimitz (2000) identified four levels of knowing: (i) awareness of systems and system laws, (ii) ability to denote qualitative systems structures, (iii) quantitative modelling and simulation of systems, and (iv) expertise in systems design and/or systems theory. In the most general sense, how we come to know systems is influenced by the epistemological perspective of knowing. From an empiricist perspective, systems knowledge is seen to develop through sensory perception, while from a rationalist perspective it is assumed to develop through reason. In an idealist perspective, which says that reality is fundamentally an idea, systems knowledge is considered to be mentally constructed, immaterial and subjective, while in a structuralist perspective systems knowledge is proposed to be embedded in higher mental, linguistic, social and/or cultural structures (Niehaves, 2007).

The epistemological assumptions made by different researchers result in an epistemological pluralism. In the context of information systems research, Becker and Niehaves (2007) showed how epistemological assumptions substantially influence the understanding of such concepts as validity, reliability or quality of research, and that studying the same phenomenon starting out from different epistemological platforms does not necessarily ensure mutual understanding. Möbus (1996) discussed a specific epistemology of intelligent design and modelling environments.

\subsection{Platforms of systems science}

General systems science (GSS) is committed to the investigation of systems, which exist naturally or are created artificially, and which altogether cover a very wide range of kind, scale, and behaviour (Mesarović, 1971). GSS is concerned with generic problems (such as boundary, definition, coherence, complexity, and invariance) from both theoretical and practical perspectives (Jamshidi, 1996), and investigates generic (paradigmatic) system attributes (Gaines, 1977). It has explicated a system concept that seems to unify the interests of researchers in this area (Marchal, 1975). The endeavour is to bring the empirical (substances, observations, laws, and facts) and the rational (assumptions, concepts, theories, and knowledge) aspects into synergy. There have been many competing views, theories, concepts, methodologies, approaches, and classifications within the current knowledge platform of system science (Bunge, 1979).

Originally, system thinking was claimed to be discipline independent (Checkland, 1999). Several branches of system thinking have been formed later in reaction to what was seen as limitations of existing theories (Bahill and Gissing, 1998). It was argued that systems science needs to integrate four basic components: (i) the science of description, (ii) the science of generic design, (iii) the science of complexity, and (iv) the science of action (Warfield, 2003). 
Nevertheless, the fundamental problem of general systems theory is still open (Braha et al., 2006). The holistic view on systems implies that not only the technical constituents (hardware, software, and cyberware), but also the associated constituents of the whole (humans, organization, and processes) should be considered.

\subsection{Overall systems theories}

Study of systems requires a theoretical framework that includes three structures: (i) syntax (rules for expressing system descriptions and specifications), (ii) semantics (mathematical models for interpreting syntactic expressions), and (iii) environment (real, simulated or imagined environment for contextualizing descriptions) (Varaiya, 2000). In the mid-1960s, Sengupta and Ackoff (1965) claimed that system theory has two major interdependent threads of analysis: (i) descriptive, i.e., how systems do behave, and (ii) normative, i.e., how systems ought to behave. Hubka (1973) combined these two aspects in his theory of technical systems. Ehrlenspiel argued that the theory of technical systems (TTS) is interlinked with the theory of design processes, theories of physical technologies, and the theories of human beings. From this scientific basis, he proposed design methodology that concurrently captures what is being created and how it is being created, form both theoretical and practical perspectives of design (Ehrlenspiel, 1994).

Various researchers proposed different activity patterns as the basis of methodologies - a first comparison of which was presented by Roth (1981). TTS classifies technical systems according to: (i) the main type of transformed quantity (material, energy, and information), (ii) their architectural and operational complexity, and (iii) level and type of abstraction applied to capture them. Many papers see TTS as the process of establishing (or designing) these kind of systems, which are, considering the philosophical interpretation of the terms, typically not complex, but complicated mechanical systems (actually, integral goal-object-process systems of a geometric-material nature) (Andreasen, 2011).

\subsection{Disciplinary knowledge assets}

While knowledge of systems science is generic (kind-independent) and holistic, knowledge of an engineered system is specific (kind-dependent) and fragmented. An overarching theory of technical systems was proposed by Hubka and Eder (1988) with the objective of supporting their synthesis (Hubka and Eder, 2002). Different kinds of engineered systems have their own epistemologies which reflect large differences, in particular when material, energy, and information processing oriented systems are compared (Beitz, 1994). Knowledge associated with engineered systems can be decomposed into three categories: (i) artefacts knowledge, (ii) processes knowledge, and (iii) contexts knowledge. Artefact knowledge extends to both architectural and operational description and explanation of systems (Thurman et al., 1997).

Process knowledge includes: (i) system-internal transformation processes, (ii) system-internal natural processes, (iii) system-related environmental processes, (iv) system-implicated (technological, production, sales, and reclaiming) processes, and (v) system-related human processes (Ramesh and Tiwana, 1999). Context knowledge is aggregated concerning both understanding and representation of explicit and implicit contexts of systems (Dourish, 2004), and practical consideration of contexts for (multi-)context-based systems (Dao-Tran, 2014). Process-based knowledge management (PKM) systems have emerged as a potential solution to support knowledge-intensive processes. However, design guidelines for developing PKM systems are minimal (Sarnikar and Deokar, 2010).

\subsection{Systems-possessed knowledge}

Systems possessing, aggregating and/or generating problem solving, or contextual knowledge have been referred to as knowledge-based systems (Akerkar and Sajja, 2010). Research in knowledgeintensive systems is done with the objective of capturing the essential knowledge of experts in formalized ways and structured forms in various systems. System-embedded knowledge, which may manifest itself in multiple forms depending on the field of application, the objective of the system, and the mechanisms of knowledge processing, has been intensively studied by knowledge engineering researchers. Knowledge-based engineering (KBE) has become the field of research that studies methodologies and technologies of capturing and re-using 
artefact-, process-, and context-related engineering knowledge (Verhagen et al., 2012).

Both inference mechanisms and factual, procedural, and professional expert knowledge bases have been addressed in knowledge-based systems research. The research published on KBE is not really extensive, but quite dispersed, according to (Verhagen and Curran, 2010). Many academic and commercial knowledge-based engineering systems have been developed to support product knowledge management over the product life-cycle and the chain of suppliers (Sainter et al., 2000). A part of research in knowledge-intensive systems (KIS), expert systems research has the longest tradition, followed by research in neural networks and genetic algorithms. A semiotics oriented knowledge framing for engineering of autonomous intelligent systems was presented by Gonçalves and Gudwin (1998). In a subset of KIS, intelligence originates in the capabilities and cooperation of multiple agents (van der Hoek and Wooldridge, 2008). The complexity of KIS is growing and various frameworks have been proposed for classifying them based on complexity (Meyer and Curley, 1991). The epistemological status of knowledge possessed by KIS has not yet been studied comprehensively.

\section{Research in systems methodology}

The debate on the definition of systems engineering has been ongoing for several decades without conclusion (INCOSE, 2007). What has been accepted is that SE is a systematic, goal-driven, knowledgeintensive process that needs methodological support and assets (Rhodes and Hastings, 2004). The subdomains of research in CTSs methodologies are shown in Fig. 5, within which research has many foci and addresses many objectives.

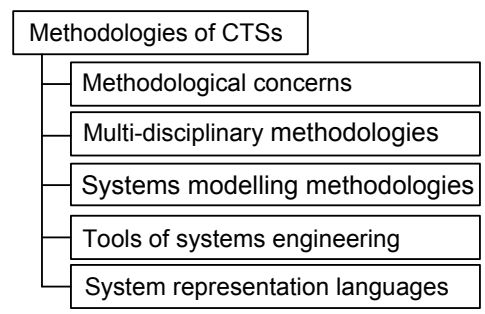

Fig. 5 Subdomains of research in methodologies of CTSs

\subsection{Methodological concerns}

Different systems development methodologies have been proposed based on: (i) a science paradigm, (ii) the systems paradigms, and (iii) the metasystem paradigm (Wynekoop and Russo, 1997). Among these are: (i) internal and external methodologies, (ii) hard system and soft system methodologies, (iii) system synthesis (modelling), and (iv) system (behavioural) investigation methodologies. In the context of CTSs, internal methodologies are about how systems can implement their planned objectives, while external methodologies concern implementation and utilization of systems (Oliga, 1988). Hard systems methodologies apply systematic decomposition to identify parts of the world as systems, as well as to establish them based on scientific laws and facts in reductionist and positivist manners.

Functionalism has been identified as the foundation and overall optimization as the objective of the efforts. On the other side, soft systems methodology (SSM) imposes a holistic perspective and promotes an action-oriented process of inquiry for tackling problematical and messy situations of all kinds, in which users learn their way from finding out about the situation to taking action to improve it. In the context of CTSs, researchers studied the systems not only within their boundaries, but also their interactions with the embedding environment, following the lines drawn up by Checkland and Poulter (2010). The usefulness of SSM in the development of information systems has been discussed by Winter et al. (1995).

\subsection{Multi-disciplinary development methodologies}

A complex system approach to design and implementation of systems involves recognizing many differences with respect to traditional engineering practices as well as to natural evolutionary processes (M'Pherson, 1980). Engineering of CTSs needs the integration of the knowledge, but also of the methodologies of multiple disciplines. Modern industrial automation systems depend on the effective and efficient cooperation of several engineering disciplines, e.g., mechanical, electrical, and software engineering, as discussed by Mordinyi et al. (2012). Collaborative engineering research tries to synthesize the knowledge of multiple disciplines and to integrate specialty groups into a coordinated team effort 
towards a structured development process that proceeds from concept development to production and operation (Horváth et al., 2010). Due to the differences in nature, development of systems assumes tailored methodologies (Wynekoop and Russo, 1997).

Besides information systems development, another example of the need for tailored multidisciplinary methodologies is system of systems developments (Jackson and Keys, 1984). System of systems engineering (SoSE) is an emerging area within systems engineering (Dagli and Kilicay-Ergin, 2008) and beyond (Jackson, 1990). It was recognized a decade ago that systems engineering of an individual system is different than the systems engineering required for a system of systems, but Sheard (2006) found that there were no dedicated SoSE methodologies at that time. It was suggested by Haimes (2012) that complex systems of systems could be modelled with phantom system models. Integrated multi-view modelling is claimed to be of paramount importance in the contexts of advance mechatronics systems, embedded systems (Persson et al., 2013), and cyber-physical systems (Derler et al., 2012).

\subsection{Systems modelling methodologies}

Systems engineering seeks to produce unique and well-behaved systems, whose behaviour can be predicted and encapsulated by precise description. Modelling is a traditional means of system development, but it poses many challenges in the context of CTSs due to their large scale and complexity, the different phases of the life cycle of systems, and the large variety of aspects of modelling. In fact, a detailed survey could not be included in this paper because of the wide spectrum of the proposed computational modelling methodologies. Kushner et al. (2001) compared three system modelling methodologies, namely: (i) Chen's entity-relationship modelling, (ii) Shlaer and Mellors' information modelling, and (iii) Rumbaugh's object modelling methodology, which all allow generalization hierarchy, but which do not all equally support aggregation.

Various modes based on Markov processes and their embedded Markov chains, Petri nets, queuing networks, automata, and finite-state machines, finitely recursive processes, min-max algebra models, and discrete event simulation and generalized semi-Markov processes were discussed and compared in (Cao and Ho, 1990). Integrated multi-aspect modelling, transformation between stage and aspects models, and handling modelling abstractions are only partially solved and are issues for current research. Fuzzy system modelling has earned a lot of attention over the last two decades (Yager, 1994). Gamification- and natural analogy-based modelling has been applied where not only the technical processes, but also the environmental interactions of CTSs are considered (Harms, 2011). Together with model-based development of CTSs, model-based reasoning and control in systems (Nersessian, 2006), model-based verification and validation, and multi-aspect modelling of system of systems are clearly an observable branch in current research (Iivari and Maansaari, 1998). The foundation of many current system modelling methodologies is state-space modelling.

\subsection{Tools of systems engineering}

Systems engineering is a discipline that solves problems in various domains, at different levels, and with ever increasing complexity, and with new challenges for modelling (Sinha et al., 2001). Amongst others, Booton and Ramo (1984) argued that development of systems engineering can be thanked for the powerful tools that have been implemented. However, each engineering specialty has developed a set of specialized tools and facilities to aid in the design and manufacture of its associated products. Therefore, the arsenal of tools has become incomprehensibly broad, like those of the procedures and methods.

Four broad categories of systems engineering tools have been identified: (i) administrative (information handling) tools, (ii) creative (representation and modelling) tools, (iii) assessment and decision making tools, and (iv) realization and production tools. Representatives of creative tools are virtual prototyping tools (Ferretti et al., 2004). Analysisbased system assessment tools are based on the fundamental assumption of the systems discipline that the internal functional behaviour of the component, as measured at its interfaces, can be described by a mathematical model depending on how the component is interconnected with other components (WoodHarper and Fitzgerald, 1982), or with the environment (Finnveden and Moberg, 2005). Various tools have been developed for modelling and simulation of 
hybrid systems in recent years, such as Matlab, Simulink, LabView, Modelica, Dymola, and Stateflow (Carloni et al., 2004), in addition to the dedicated tools for software systems and information systems (Cellier et al., 2007). The various Petri net based approaches for discrete event systems have been discussed by Holloway et al. (1997).

\subsection{Systems representation languages}

Passive document-centric approaches of the near-past practice have been replaced by active scheme-oriented representation approaches. For instance, a language for modelling structure, behaviour and function of CTSs was proposed by Goel et al. (2009). The notions (such as syntax and semantics) of systems modelling languages have been discussed by Harel and Rumpe (2004). The unified modelling language (UML) was proposed as a representation language for software engineering some three decades ago (Booton and Ramo, 1984; Booch et al., 1996). As a general-purpose textual and visual representation for hybrid systems the system modelling language (SML) has been developed (Behjati et al., 2011). It has many variations such as the OMG systems modelling language (SysML) and the object process methodology for conceptual representation. These variants have been compared by Grobshtein $e t$ al. (2007). To enhance its comprehensive architecture representation capabilities SysML has been extended with the architecture analysis and design language (AADL) (Costa et al., 2009). Though the development of tools and languages of system modelling has been driven by different objectives and principles, a kind of methodological complementarism was also observed, and the role of this in systems research was analysed by Brocklesby (1995).

\section{Research in the creation of systems}

The recognized subdomains of research in the creation of systems and implementing systems functionalities are graphically depicted in Fig. 6. It should be mentioned that research decomposes to the study of both generic functionalities and specific functionalities. Below we consider only the generic transformational functionalities.

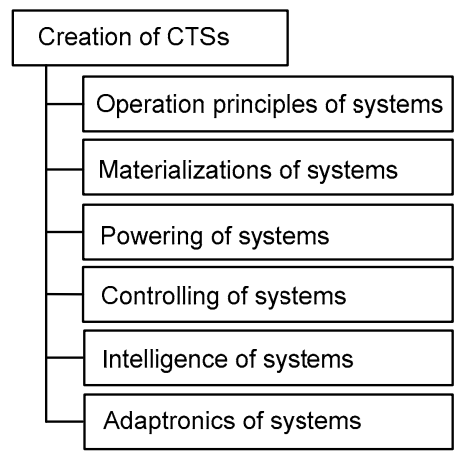

Fig. 6 Subdomains of research in creation of CTSs

\subsection{Operation principles of systems}

It has been showed that, according to their generic behaviour, systems belong to three categories: (i) simple, (ii) complicated, and (iii) complex, and that the third category is not approachable by the methods of scientific reductionism (Cotsaftis, 2005). Complex behaviours cannot be just reduced to the functions and effects components. On the word of (Dori, 2003), function is a problem-oriented concept, specifying what goal the system is expected to achieve, while architecture is a solution-oriented concept, specifying how the function of a system is to be achieved by a specific architecture. It was discussed in (Vermaas and Houkes, 2006) that researchers see technical functions as a bridge between the intentional and structural nature of systems, operations as between the structural and the physical nature, and behaviour as between the physical and the observational nature.

According to the argumentation of (Ottens, 2007), three elements, namely: (i) the technical constituents, (ii) the social factors and circumstances, and (iii) the human actors should be captured when modelling the functioning of socially embedded technical systems. Mitchell and Sundstrom (1997) gave an overview of the design issues and research approaches concerning human interaction with complex systems. Minai et al. (2010) suggested that complex system engineering does not primarily seek to produce predictable, stable behaviour within carefully constrained situations, but rather to obtain systems capable of adaptation, change, and novelty, even surprise. Importing natural analogies to enhance functionalities of technical systems is being done under key terms such as biomimicry and biologicallyinspired engineering (Vincent and Mann, 2002). 


\subsection{Materialization of technical systems}

Research related to materialization of CTSs seems to extend to five subdomains: (i) advanced structural materials for system embodiment, (ii) innovative functional materials for systems, (iii) surrogates for rare system materials, (iv) dematerialization, and (v) bio/nano materials for systems (Ashby and Cebon, 1993). According to (Itoh, 1991), the traditional issues of producing and using structural materials for embodiment appear in new contexts in the case of complex systems, such as large space systems, due to the effects of the dynamically changing environments. Shape memory alloys and polymers, hybrid matrix materials, smart textiles, dielectric elastomers, and magnetorheological materials are just a limited number of examples of smart materials that researchers are developing and investigating.

There is a move towards an emerging new field of integrated systems materials engineering (SME) (Yang and Tarascon, 2012). For instance, researchers suggested intelligent structures for the aerospace industry (Crawley, 1994). SME emphasizes the study of interactions between materialization of system components, and intends to develop functional materials to enhance the performance at a system level (Tani et al., 1998). Establishment of databases for novel functional materials and capturing their functional affordances together with the physical attributes is a new challenge (Sapuan, 2001). Research in next-generation batteries and fuel cells, and smartly behaving materials is rapidly growing in the context of CTSs (Leng et al., 2009), as well as research in biomaterials and nanomaterials (Kang et al., 2006).

\subsection{Powering of technical systems}

The following objectives could be identified in this subdomain of research: (i) electric energy transfer networks as CTSs, (ii) replaceable energy storage solutions, (iii) renewable energy sources in CTSs, (iv) power consumption optimization in networked CTSs, and (v) wireless energy transfer in/to CTSs. Researchers address the issues of distributed energy harvesting and transforming electric power systems into heterogeneous and distributed generation networks (Priya and Inman, 2009). Materials and energy research are interconnected in development of high-performance batteries (Jha, 2012). For instance, research in electrochemical energy storage and supercapacitors investigates both material and efficiency related issues. Equipping product with local renewable energy sources is a hot topic of product engineering (Deshmukh and Deshmukh, 2008). Utilization of renewable energy sources and their integration has become a central theme of research in future energy systems (Liserre et al., 2010). Electromagnetic fields-based transmission is also an important topic for current research. It seems that energy supply for systems operating in remote locations over long periods without intervention will develop into a research issue.

\subsection{Controlling of technical systems}

The concepts of cybernetics have been used to differentiate between: (i) the first-order cybernetic systems (whose control and communication is regulated by feedback mechanisms), (ii) the second-order cybernetic systems (which are characterized by selforganization), and (iii) the third-order cybernetic systems (which feature intelligence, or artificial mind and consciousness) (Mayne, 1998). The research in the control of systems shows that there are no generic solutions, but only specific ones, due to the extremely large variety of the objectives, manifestations, and environments of systems (Zhang et al., 2008). The range of methodologies proposed and studied in applications is large, from logic based predefined control, through adaptive control, to self-managed intelligent control (Holland, 2006). Most of the control theories and tools have been developed for such systems whose evolution is described by smooth linear or nonlinear state transition functions (Bemporad and Morari, 1999). Emergence and evolution are, however, against the classical principles of control engineering that makes a clear distinction between the design, production, and operation phases of the existence of systems (Tipsuwan and Chow, 2003). In the case of self-adaptive systems no sharp demarcation of the three phases is found possible. Soft computing methodologies have been proposed for multistage supervisory control of complex systems (Stylios et al., 1999).

\subsection{Intelligence of systems}

In the past, research focused on many different areas of implementation of artificial reasoning and 
intelligence technologies in complex systems: (i) formal (the first-, second-, and higher-order logic), (ii) rule-based symbolic reasoning, (iii) fuzzy logic, (iv) genetic algorithms, (v) case-based reasoning, (vi) neural networks, (vii) natural analogy-based mechanisms, (viii) expert systems, and (ix) multi-agentbased systems. In the last two decades, a strong integration of technologies can be observed in the field of intelligent engineering systems (Jain and Jain, 1997). New technologies such as smart sensor networks, collaborative agent technologies, big data management, and semantic network technologies complete the range of technologies that are addressed in research and used in development (Albus, 2001). Concerns for research are: (i) distribution of decisions, (ii) timing/scheduling of reasoning processes, (iii) artificial immune systems in industrial applications, and (iv) interaction and communication via brain-computer interfaces with intelligent systems (Nijholt and Tan, 2008). Personalization and social intelligence is a hot issue in multi-robot and human-robot systems (Lueth et al., 1994). Networking of intelligent robots, development of proactive service robotics systems, and application specific cyber-physical systems are all studied intensively (Luo et al., 2003). The current trend in the research of intelligent systems indicates that more integration and diversification has been achieved over the last decades and that this trend will most probably continues in the coming years (Chaib-Draa et al., 1992).

\subsection{Adaptronics of systems}

The ability of a system to physically (structurally and procedurally) change (adapt) to the new optimum, potentially even while in use, is defined as adaptability by Chmarra et al. (2008). Coined by German researchers, the term adaptronics designates a system wherein at least one element is applied in a multifunctional way and the whole structure shows autonomic adaptive characteristics under different conditions (Neumann, 2007). Adaptation is seen as a conditioned self-capability of a class of systems (Benyon and Murray, 1993). In the literature, evolution and evolvability of engineered systems are also often studied as system properties (Janocha, 2007). Traditional interpretation of the evolution of an engineered system considers the changes to a system, which are made by the system designers at design time as a result of changed requirements from one release of the system to the next. Evolvability is studied based on the assumption that systems have intelligence and self-adaptability to adapt themselves automatically, either of which based on run-time environmental changes, and it has received attention in the context of hardware systems (Torresen, 2004), embedded systems (van de Laar et al., 2011), and software systems (Cheng et al., 2009).

\section{Research in systems axiology}

Systems axiology research concentrates on the relationships between systems and society with the objective of studying: (i) the nature that value systems represent and create, (ii) the value judgments and humanistic concerns related to systems, (iii) the development and embedding of systems in the fabric of nature, society, and infrastructure, and (iv) the impacts of systems on individuals, social entities, and cultures. The subdomains of research are shown in Fig. 7.

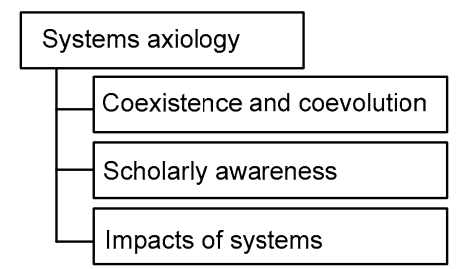

Fig. 7 Subdomains of systems axiology

\subsection{Coexistence and coevolution of systems and society}

The interaction of CTSs and their coevolution with society are current hot topics of research. In an early paper, Sutherland (1978) proposed two strategies to reduce the disparity between the claims that systems science promised and what it has actually accomplished in a social context, which focus on: (i) increasing obedience to the set of procedural dictates under which the system philosophy was initially formulated, and (ii) bringing the rates of development of system theory and system methodology into better balance, such that system ontology becomes in part responsive to system epistemology. Due to the fact that engineered systems are socially constructed, systems and society are in a relationship that cannot be separated (Bauschspies et al., 2006). 
Various authors considered the intrinsic relationships between science, technology, and society as a basis (McGinn, 1991). Some of the important relationships studied are those such as automation (Mayer, 2008), reliability (Schulman et al., 2004), ecology (Jørgensen et al., 1992), virtualization (Ray, 2005), and connectivity (Farber, 2002), which altogether bring the research issue of dependability to the fore. From a pragmatic point of view, high-reliability management of large hazardous technical systems (Horváth and Matthews, 2004) and optimal utilization of the critical service infrastructures of society (Roe $e t$ al., 2005) are the focus of investigation due to the obvious interest in the strategy of managing performance fluctuations. Social and human impacts of the trends of automation and information have grown to be distinct research foci (Bates, 1990). The human-systems relationship has been studied from the following aspects: (i) human as system creator and supervisor, (ii) human-system cooperation and interfunctionality, and (iii) presence/inclusion of autonomous intelligent systems (Antsaklis et al., 1993).

\subsection{Scholarly awareness of systems}

It seems that research interest is divided between contents for systems engineering educational programs, and the advanced enabling environments/tools for systems education. Education programs in systems science and engineering can broadly be sorted into: (i) systems theories, (ii) systems engineering, (iii) manufacturing systems, (iv) industrial engineering, (v) technology policy and management, (vi) operations research, (vii) systems logistics, and (viii) engineering management categories (Ng, 2004). Four levels of education have been identified: (i) individual, (ii) organizational, (iii) inter-organizational, and (iv) network level (Romano and Secundo, 2009). As analysed by Dixit and Valerdi (2007), challenges exist in the development of systems engineering as a recognized profession, because the problem space in which it operates is very broad, and many principles are borrowed from other disciplines. It was argued by Kieras (1988) that the choice of what should be taught about the internal workings of equipment is critical, especially when the equipment user is expected to recognize malfunctions, and either compensate for them, or repair them.

Five competencies for system engineers have been identified by Hall (1962): (i) affinity with sys- tems thinking, (ii) creative capabilities, (iii) faculty of judgment, (iv) facility in human relations, and (v) a gift for expression. Course contents development is challenged by the theory-practice duality, that is the breadth and depth of theoretical system science, and the know-how of development and application of systems, which is becoming more complex as engineered systems are becoming complex (Foster et al., 2001). Researchers claimed that general systems theory cannot be adequately understood or applied by undergraduate or graduate students until their thinking has reached a particular developmental level and have integrated particular epistemological assumptions into their world views (van Dam et al., 2007). They also considered what knowledge of systems should be communicated to, and how systems related competencies can be built up for non-technical individuals and broader non-expert communities (Grippa and Secundo, 2009).

With the advent of personal computers, computer support manifested in three main fields: (i) acquisition and analysis of data from experiment, (ii) simulation of operational workflows and system behaviours, and (iii) computer-aided learning tutorials (Heikal and Peeling, 1991). Among others, Bransford et al. (1989) proposed the consideration of: (i) learner centred, (ii) knowledge centred, (iii) community centred, and (iv) assessment centred learning environments/tools, which are conceptualized as a system of interconnected components. In addition to networking, recent technological developments have made simulations and gamifications crucial parts of system learning (Prensky, 2003). Recent efforts are towards adaptive learning systems based on semantic web languages (Wang and Chen, 2008), and towards web-hosted collaborative intelligent tutorial systems, that also benefit from the affordances of virtual and mixed reality technologies (Schaf et al., 2007). Virtual laboratory platforms and remotely accessible physical laboratories were proposed for experimentation in intensive educational contexts (Arango et al., 2007).

\subsection{Impacts of systems}

The dependence of systems on their surroundings is studied under the assumption that even autonomous systems have multi-fold teleological and technical relationships with their environment (Liker 
et al., 1993). As the embedding environment changes, the requirements posed by the environment to the system are also changing, as well as the conditions for the system operation. Three major impact fields have been identified for CTSs: (i) ecological impacts, (ii) socio-economic impacts, and (iii) cognitive-emotive impacts. Ecological impacts have been variously formulated and interpreted with respect to the living/ organic and the non-living/abiotic environments, and considering a broader/narrower effect zone and longer/shorter time windows (Allen et al., 2003). Literature shows that eventually there are as many kinds of ecological impacts as systems, or even more. Ecological engineering has developed as the discipline of studying the phenomena and developing principles for engineering under ecological constraints (Mitsch, 1996). Sustainability constraints have been interpreted as system boundaries (Ny et al., 2006). Correlation was found between the economic and ecological performance, which can be influenced on a multiple level of system innovation (Boons and Wagner, 2009). The challenge of eco-innovation was addressed (Rennings, 2000), as well as the role of sustainable design and development in achieving eco-efficiency (Braungart et al., 2007).

It seems that a central issue for research in the subdomain of socio-economic impacts is the social impact of computerization (Forester, 1992), or using information and communication technologies (Perrolle, 1988). The objective of research ranges from the philosophical foundations (O'Donnell and Henriksen, 2002) and influences on organizations (Sviokla, 1990), through the effects of connectivity (Kraut et al., 1998) and information sharing (Griffiths and Parke, 2002), to security (Whitman, 2003) and privacy (Malhotra et al., 2004). The methods and measures of assessing social impacts have turned up frequently as research interests, in various contexts, for a long time (Wolf, 1983). Though computerization receives growing attention, the social impacts of other engineering systems (e.g., production systems) (Schmid and Verlage, 2002), have also been widely studied. Of importance is the observation of (Bugliarello, 1991) that "many engineering developments of this century with immense impacts on our lives have not been accompanied by realistic engineering views of those impacts on the social fabric or the environment".
The social impact of computerization and its study have been found to be enormous, and have been complemented with the study of economic aspects (Litan and Rivlin, 2001). Cognitive-emotive impacts are also receiving attention (Madni, 2010). Since the socio-cultural impacts of CTSs starts with their interaction with and the influence on human individuals and communities, perceptive, cognitive and emotional effects of technologies and systems have been studied in countless forms (Subrahmanyam et al., 2000). Using computer-aided engineering systems in creative industrial product development processes is also a prominent study area (Norman, 1997). The research efforts in this subdomain can be exemplified by very different studies such as the effect of learning systems (Domínguez et al., 2013), or road traffic systems (Gish et al., 1999). With the ultimate goal of reducing or neutralization of impact, various measures have been proposed (Moon et al., 2004).

\section{Research in systems manifestations}

The literature shows that there are two main dimensions of research in this domain which appear in integration: (i) manifestation from organizational and structural perspectives, and (ii) manifestation from operational and behavioural perspectives. The subdomains of research in manifestation of CTSs are shown in Fig. 8.

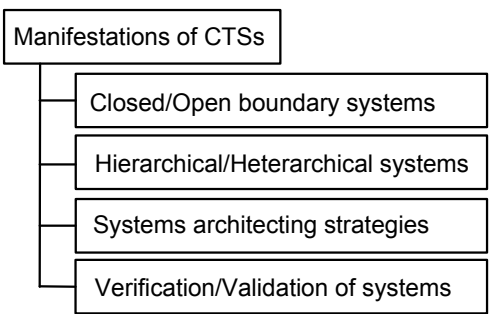

Fig. 8 Subdomains of research in manifestation of CTSs

\subsection{Closed and open system manifestations}

von Bertalanffy (1950b) noted that biological systems are 'open' in that they have to interact with the environment (exchange matter and energy in order to stay alive). CTSs are open systems in this sense, but in addition they may have varying system boundaries, structure, and behaviour on different scales (Hewitt, 1985). In current research, the 
Internet/WWW is the ultimate open system, which shows the highest extensibility (anyone can create a new Web server/page, become a part of the Web, and contribute to it immediately) (Dargan and Hermes, 1997). Members of an open system may leave a particular structure and affiliate with other systems temporarily or permanently. However, not all distributed systems are automatically open systems (Yoshida et al., 2004).

Seven aspects were proposed by Minar (2002) to evaluate the characteristics of distributed systems: (i) manageability, (ii) information coherence, (iii) extensibility, (iv) fault tolerance, (v) security, (vi) resistance, and (vii) scalability. A volatile nature is a distinguishing characteristic of open systems, and has influence on both the architecture and the management. Being influenced by interoperability and interfacing concerns, ad hoc extensibility of open systems is a major issue. Hierarchical systems have been found extensible more easily, but less flexibly, than open decentralized systems (Zhang and Li, 2010). Other widely studied characteristics of open systems are decentralization and scalability (Jogalekar and Woodside, 2000). Truly decentralized systems are functionally, structurally and decision-wise dispersed. Scalability studies address issues related to the limits and trends of growth of systems.

\subsection{Hierarchical and heterarchical system manifestations}

The term 'hierarchical system' has been used in research in several different ways, referring to classifications, objectives, concepts, controls, functions, tasks, compositions, and structures (Voorhees, 1983). Hierarchy has been studied as an area of general systems theory (Salthe, 2012). Proposed hierarchical system theories have been applied to develop representations and manage the decomposition of a system into a hierarchical structure of subsystems (Smith and Sage, 1973). It was proposed by Allen and Mistree (1993) that the hierarchical or heterarchical nature of a system should be considered in the design process. Hierarchical structures were found efficient in control of and information processing in complex systems (Conant, 1974). It was shown that a hierarchical structure leads to an effective saturation of the complexity value with increasing number of lower levels (Ceccatto and Huberman, 1988). It is proposed that hierarchical system theory (dealing with constraints bearing on a system), as a polar opposite of self-organization theory (looking at a changing system from inside) could in fact be taken to be complementary, since each supplies what the other lacks in understanding systems (Salthe and Matsuno, 1995).

\subsection{Systems architecting strategies}

It was argued by Maier (1996) that systems architecting activities are distinct from other system engineering activities. Traditionally, architecting was seen as a process of structuring and integrating the components of a system, and their architectural and operational interrelationships (Ezell and Crowther, 2007). With the appearance of system of systems, its scope extended to configuration and integration of systems into higher level configurations. Modularization of systems has been recognized as an approach providing both technical and economic advantages. Research addresses the generic principles of modularization and creates some levels of independence from design and implementation viewpoints, but raises issues of compatibility, interfacing, and system testing.

Typical modular systems are produced by the computer industry, where modularization includes hardware, software, and cyberware. There are studies on how modularization supports division of cognitive labour, enables parallel work, and offers flexibility and variability. As discussed by Baldwin and Clark (2006), three basic types of modularity have been considered: (i) modularity-in-design, (ii) modularityin-production, and (iii) modularity-in-use. Various methods have been developed, for instance, the design structure matrix approach, to define modules based on mapping the relationships between system parameters. System composition based on selecting and configuring (off-the-shelf) components, and platform-based architecting are other approaches (Gössler et al., 2007).

\subsection{Verification/Validation of systems}

The objective of verification and validation (V\&V) research is to facilitate dependable CTSs (Wise and Wise, 1993). V\&V refers to a family of informed, systematic, and critical (rational or empirical) examinations and investigations that include: 
(i) justification and validation that are usually rational and applied to system theories, rules, and facts, (ii) observation and experimentation that are typically empirical and explorative, (iii) interrogation and intervention that are applied to various stakeholders and manifestations of systems, or to parts thereof, and (iv) analysis, simulation, and optimization that are based on virtual models and replicas of systems using computer-aided tools. Verification is defined as the confirmation by examination and provision of objective evidence that the objectives of a system development have been fulfilled (Goubault et al., 2006). Validation is defined as proving that a system fulfils particular requirements for a specific intended use, and it performs as it is expected in the presumed context (Heerink and Brinksma, 1995). Complementing each other, methods and tools of V\&V serve as means of 'scrutinizing' CTSs from conceptual, materialization, operational, structural, and behavioural aspects. A wide variety of studies has been conducted on each of these tasks, ranging from underpinning theories through supporting methods to supporting tools and systems. V\&V has an emphasized role in the context of mission critical systems and high-impact (safety-critical) CTSs (Feiler, 2009).

Nevertheless, ensuring that such systems meet their predefined requirements and perform as expected is a challenging issue (Gonzalez and Barr, 2000). It has been shown that conventional V\&V methods and tools such as testing and simulation have become less useful in many modern engineering disciplines or even not always applicable to specific (e.g., intelligent) systems. Often early prototypes are used for requirement validation (Andrews and Goeddel, 1994). Over the years there has been an increasing research effort directed towards the automatic verification of infinite state systems, such as timed automata, hybrid automata, data-independent systems, and relational automata (Alur et al., 1996). Automatic verification of embedded systems includes model-checking procedures checking safety, liveness, time-bounded and duration requirements of digital controllers, schedulers and distributed algorithms (Abdulla and Jonsson, 2003). Researchers adopted the assume-guarantee approach to verification, where both the assumptions made about system components and the guarantees that they provide are regular safety properties, represented by finite automata (Kwiatkowska et al., 2010).

\section{Some reflections and conclusions}

Systems science is concerned with scientific exploration of and theorizing about systems, and it is seen both as a conceptual system of abstract ideas and as a real system of practical knowledge and know-how. General system theory provides the doctrine of principles applicable to all systems (Hofkirchner and Schafranek, 2011). The engine behind the advancement of systems science and general system theory is foundational research, which has not been sufficiently investigated in the past from an ontological perspective.

The objective of this paper has been to contribute to the elimination of this bottleneck and to argue for further research. It has been found that an extremely large number of publications are available concerning many research domains. However, it is difficult to identify specific foci in the domains. For this reason the proposed classification has many subjective elements and imbalance in terms of evidences underpinning particular claims. Although the intention was clearly to demarcate the content of research from the ways research was conducted, it was not possible in every single case.

The proposed classification scheme of foundational research in CTSs is shown in Fig. 9. It shows the abstract categories, as well as the research domains and subdomains. Obviously, various branches of research can be identified within each subdomain, but this effort could be started, but not finished in this paper. This is however difficult for the reason that many research works have strongly interdisciplinary or multidisciplinary character. Just to mention one illustrative example, the research of (Harrison and West, 2000) extends to at least three research subdomains that have been identified in our paper. Contemporary system engineering also includes domains of research, such as engineering project management and operations research, which the classical one does not. Engineering of information systems and in particular software systems is conducted according to multiple, competing methodologies (Wangler and Backlund, 2005). 


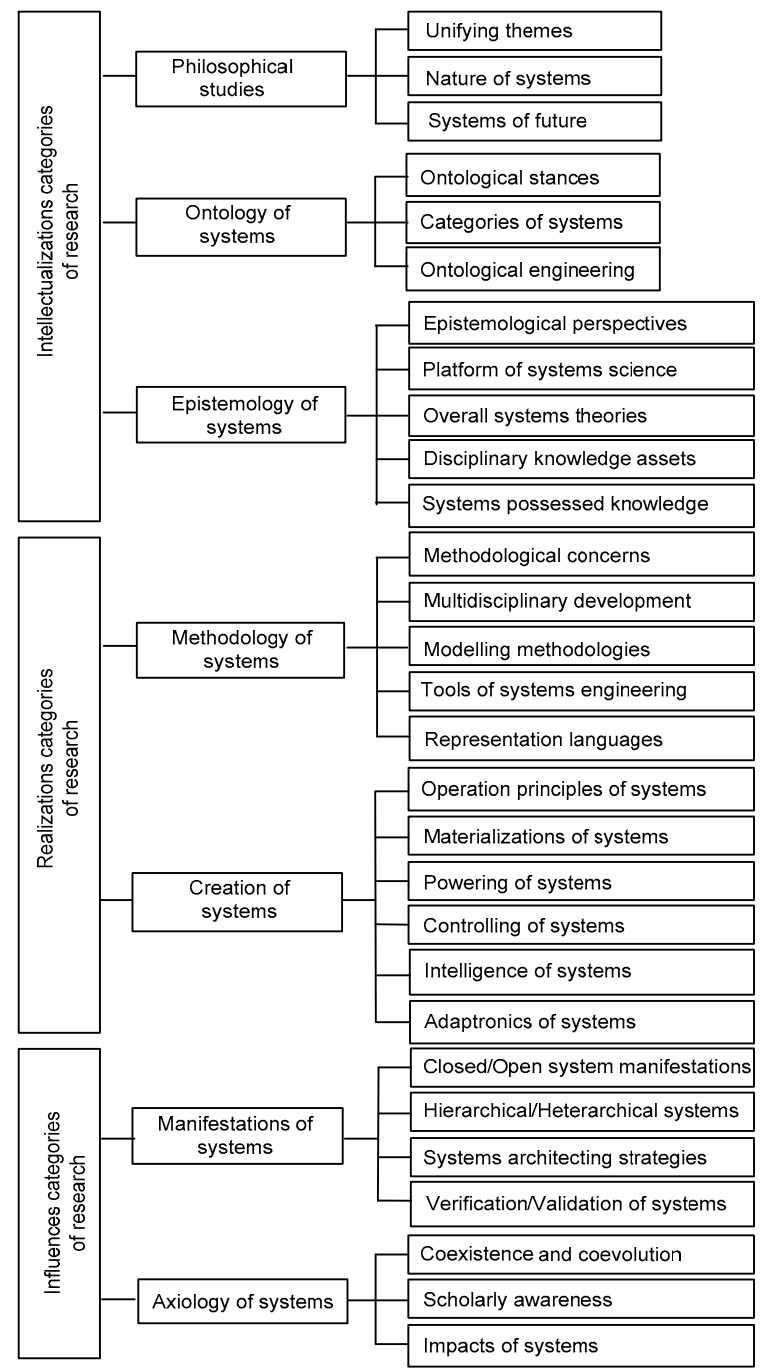

Fig. 9 Mapping of the domains of research related to CTSs

Further study is needed to learn what other genres of systems the proposed classification can be applied to, and to explore what modifications it needs in order to become applicable for the survey of foundational research in other domains of systems science and engineering. The proposed classification scheme entails the need for a reasoning model about the operative (practice-driven) research approaches of CTSs - a challenge which will be addressed in our follow up research. In addition, we will be engaged with the application and possible refinement of the proposed reasoning model for cyber-physical systems (Baheti and Gill, 2011) and Internet-of-things infrastructure-based systems (Boley and Chang, 2007) in the second phase of our work.

\section{References}

Abdulla, P.A., Jonsson, B., 2003. Model checking of systems with many identical timed processes. Theoretical Computer Science, 290(1):241-264. [doi:10.1016/S03043975(01)00330-9]

Aberer, K., Hauswirth, M., 2001. Peer-to-peer information systems: concepts and models, state-of-the-art, and future systems. ACM SIGSOFT Software Engineering Notes, 26(5):326-327. [doi:10.1145/503271.503268]

Ackoff, R.L., 1974. The systems revolution. Long Range Planning, 7(6):2-20. [doi:10.1016/0024-6301(74)90127 -7]

Ackoff, R.L., 1994. Systems thinking and thinking systems. System Dynamics Review, 10(2-3):175-188. [doi:10. 1002/sdr.4260100206]

Akerkar, R., Sajja, P., 2010. Knowledge-based Systems. Jones $\&$ Bartlett Publishers.

Albus, J.S., 2001. Engineering of Mind: an Introduction to the Science of Intelligent Systems. Wiley, New York.

Allen, J., Mistree, F., 1993. Design of hierarchical and non-hierarchical systems. Proceedings of the NSF Design and Manufacturing Systems Conference, Charlotte, NC, p.443-447.

Allen, T.F., Giampietro, M., Little, A.M., 2003. Distinguishing ecological engineering from environmental engineering. Ecological Engineering, 20(5):389-407. [doi:10.1016/j. ecoleng.2003.08.007]

Alur, R., Henzinger, T.A., Ho, P.H., 1996. Automatic symbolic verification of embedded systems. IEEE Transactions on Software Engineering, 22(3):181-201. [doi:10.1109/32. 489079]

Andreasen, M.M., 2011. 45 years with design methodology. Journal of Engineering Design, 22(5):293-332. [doi:10. 1080/09544828.2010.538040]

Andrews, B.A., Goeddel, W.C., 1994. Using rapid prototypes for early requirements validation. Proceedings of the INCOSE International Symposium, 4(1):98-105. [doi:10. 1002/j.2334-5837.1994.tb01689.x]

Antsaklis, P.J., Lemmon, M.D., Stiver, J.A., 1993. Learning to be autonomous: intelligent supervisory control. Intelligent Control Systems: Theory and Applications, p.28-62.

Arango, F., Chang, C., Esche, S.K., et al., 2007. A scenario for collaborative learning in virtual engineering laboratories. Proceedings of the 37th Annual Frontiers in Education Conference-Global Engineering: Knowledge without Borders, Opportunities without Passports, IEEE, F3G-7.

Ashby, M.F., Cebon, D., 1993. Materials selection in mechanical design. Le Journal de Physique IV, 3(C7):C7-1.

Badillo-Piña, I., Tejeida-Padilla, R., Morales-Matamoros, O., 2011. Toward a systems science structure. Proceedings of the 55th Annual Meeting of ISSS, Hull, UK, 55(1).

Baheti, R., Gill, H., 2011. Cyber-physical systems: the impact of control technology. IEEE Control Systems Society, 1:161-166.

Bahill, A.T., Gissing, B., 1998. Re-evaluating systems engineering concepts using systems thinking. IEEE Transactions on Systems, Man, and Cybernetics, Part C: 
Applications and Reviews, 28(4):516-527. [doi:10.1109/ 5326.725338]

Bahm, A.J., 1981. Five types of systems philosophy. International Journal of General System, 6(4):233-237. [doi:10. 1080/03081078108934801]

Baldwin, C.Y., Clark, K.B., 2006. Modularity in the Design of Complex Engineering Systems. Springer, Berlin, p.175205.

Bates, B.J., 1990. Information systems and society: potential impacts of alternative structures. Telecommunications Policy, 14(2):151-158. [doi:10.1016/0308-5961(90) 90032-M]

Bauschspies, W.K., Croissant, J., Restivo, S., 2006. Science, Technology and Society: a Sociological Approach. Blackwell Publishing, Malden, MA, USA.

Becker, J., Niehaves, B., 2007. Epistemological perspectives on IS research: a framework for analysing and systematizing epistemological assumptions. Information Systems Journal, 17(2):197-214. [doi:10.1111/j.1365-2575.2007. 00234.x]

Behjati, R., Yue, T., Nejati, S., et al., 2011. Extending SysML with AADL concepts for comprehensive system architecture modelling. In: Modelling Foundations and Applications. Springer, Berlin, p.236-252.

Beitz, W., 1994. Design science: the need for a scientific basis for engineering design methodology. Journal of Engineering Design, 5(2):129-133. [doi:10.1080/ 09544829408907878]

Bemporad, A., Morari, M., 1999. Control of systems integrating logic, dynamics, and constraints. Automatica, 35(3):407-427. [doi:10.1016/S0005-1098(98)00178-2]

Benyon, D., Murray, D., 1993. Developing adaptive systems to fit individual aptitudes. Proceedings of the 1st International Conference on Intelligent User Interfaces, ACM, p.115-121. [doi:10.1145/169891.169925]

Bi, Z., 2011. Revisiting system paradigms from the viewpoint of manufacturing sustainability. Sustainability, 3(9): 1323-1340. [doi:10.3390/su3091323]

Bird, S.D., 1993. Toward a taxonomy of multi-agent systems. International Journal of Man-Machine Studies, 39(4): 689-704. [doi:10.1006/imms.1993.1079]

Boley, H., Chang, E., 2007. Digital ecosystems: principles and semantics. Proceedings of the Inaugural IEEE-IES Digital EcoSystems and Technologies Conference, IEEE, p.398-403. [doi:10.1109/DEST.2007.372005]

Booch, G., Rumbaugh, J., Jacobson, I., 1996. The unified modelling language. Unix Review, 14(13):5.

Boons, F., Wagner, M., 2009. Assessing the relationship between economic and ecological performance: distinguishing system levels and the role of innovation. Ecological Economics, 68(7):1908-1914. [doi:10.1016/j. ecolecon.2009.02.012]

Booton, R.C., Ramo, S., 1984. The development of systems engineering. IEEE Transactions on Aerospace and Electronic Systems, 4:306-310. [doi:10.1109/TAES.1984. 4502055]

Borst, P., Akkermans, H., Top, J., 1997. Engineering ontologies. International Journal of Human-Computer Studies,
46(2-3):365-406. [doi:10.1006/ijhc.1996.0096]

Braha, D., Suh, N., Eppinger, S., et al., 2006. Complex Engineered Systems. Springer, Berlin, p.227-274. [doi:10. 1007/3-540-32834-3]

Bransford, J.D., Franks, J.J., Vye, N.J., et al., 1989. New approaches to instruction: because wisdom can't be told. In: Similarity and Analogical Reasoning. Cambridge University Press, Cambridge, p.470-497.

Braungart, M., McDonough, W., Bollinger, A., 2007. Cradleto-cradle design: creating healthy emissions. Journal of Cleaner Production, 15(13-14):1337-1348. [doi:10. 1016/j.jclepro.2006.08.003]

Brocklesby, J., 1995. Intervening in the cultural constitution of systems: methodological complementarism and other visions for systems research. The Journal of the Operational Research Society, 46(11):1285-1298. [doi:10. 1057/jors. 1995.178]

Bugliarello, G., 1991. The social function of engineering: a current assessment. In: Sladovich, H.E. (Ed.), Engineering as a Social Enterprise. National Academic Press, Washington DC, p.73-88.

Bunge, M.A., 1977. General systems and holism. General Systems Yearbook, 22:87-90.

Bunge, M.A., 1979. A World of Systems. Reidel, Dordrecht, Boston.

Burrell, G., Morgan, G., 1979. Sociological paradigms and organizational analysis. Heinemann, London.

Cabrera, D., Colosi, L., Lobdell, C., 2008. Systems thinking. Evaluation and Program Planning, 31(3):299-310.

Cao, X.R., Ho, Y.C., 1990. Models of discrete event dynamic systems. IEEE Control Systems Magazine, 10(4):69-76. [doi:10.1109/37.56280]

Carloni, L., Di Benedetto, M., Passerone, R., et al., 2004. Modelling Techniques, Programming Languages and Design Toolsets for Hybrid Systems. The Columbus Project, Technical Report DHS4-6.

Ceccatto, H.A., Huberman, B.A., 1988. The complexity of hierarchical systems. Physica Scripta, 37(1):145. [doi:10. 1088/0031-8949/37/1/021]

Cellier, F.E., Clauß, C., Urquía, A., 2007. Electronic circuit modelling and simulation in Modelica. Proceedings of the Sixth Eurosim Congress on Modelling and Simulation, p.1-10.

Chaib-Draa, B., Moulin, B., Mandiau, R., et al., 1992. Trends in distributed artificial intelligence. Artificial Intelligence Review, 6(1):35-66. [doi:10.1007/BF00155579]

Chandrasekaran, B., Josephson, J.R., Benjamins, V.R., 1999. What are ontologies, and why do we need them? IEEE Intelligent Systems, 14(1):20-26. [doi:10.1109/5254. 747902]

Checkland, P., 1999. Systems Thinking, Systems Practice. John Wiley, Chichester, New York.

Checkland, P., Poulter, J., 2010. Soft systems methodology. In: Reynolds, M., Holwell, S. (Eds.), Systems Approaches to Managing Change: a Practical Guide. Springer, London, p.191-242. [doi:10.1007/978-1-84882-809-4_5]

Chen, C., 1999. Visualising semantic spaces and author co-citation networks in digital libraries. Information 
Processing and Management, 35(3):401-420. [doi:10. 1016/S0306-4573(98)00068-5]

Cheng, B.H., de Lemos, R., Giese, H., et al., 2009. Software engineering for self-adaptive systems: a research roadmap. In: Software Engineering for Self-adaptive Systems. Springer, Berlin, p.1-26. [doi:10.1007/978-3642-02161-9]

Chmarra, M.K., Arts, L., Tomiyama, T., 2008. Towards adaptable architecture. Proceedings of the International Design Engineering Technical Conferences, ASME, p.367-376.

Conant, R.C., 1974. Information flows in hierarchical systems. International Journal of General Systems, 1(1):9-18. [doi:10.1080/03081077408960744]

Costa, T., Sampaio, A., Alves, G., 2009. Using SysML in systems design. Proceedings of the International Conference on Information Management, Innovation Management and Industrial Engineering, Xi'an, China, 4:615-618.

Cotsaftis, M., 2005. Beyond mechatronics, toward global machine intelligence. Proceedings of ICMT, KualaLumpur, p.6-8.

Crawley, E.F., 1994. Intelligent structures for aerospace: a technology overview and assessment. AIAA Journal, 32(8):1689-1699. [doi:10.2514/3.12161]

Dagli, C.H., Kilicay-Ergin, N., 2008. System of systems architecting. System of Systems Engineering, p.77-100. [doi:10.1002/9780470403501.ch4]

Dao-Tran, M., 2014. Distributed Nonmonotonic Multi-context Systems: Algorithms and Efficient Evaluation. PhD Thesis, Technische Universität Wien, Austria.

Dargan, P.A., Hermes, M.A., 1997. Challenges in designing open systems. Proceedings of the INCOSE International Symposium, 7(1):228-235. [doi:10.1002/j.2334-5837. 1997.tb02176.x]

Derler, P., Lee, E.A., Vincentelli, A.S., 2012. Modelling cyber-physical systems. Proceedings of the IEEE, 100(1): 13-28. [doi:10.1109/JPROC.2011.2160929]

Deshmukh, M.K., Deshmukh, S.S., 2008. Modelling of hybrid renewable energy systems. Renewable and Sustainable Energy Reviews, 12(1):235-249. [doi:10.1016/j.rser. 2006.07.011]

Dixit, I., Valerdi, R., 2007. Challenges in the development of systems engineering as a profession. INCOSE International Symposium, 17(1):124-139. [doi:10.1002/j.23345837.2007.tb02862.x]

Domínguez, A., Saenz-de-Navarrete, J., De-Marcos, L., et al., 2013. Gamifying learning experiences: practical implications and outcomes. Computers \& Education, 63: 380-392. [doi:10.1016/j.compedu.2012.12.020]

Dori, D., 2003. Conceptual modelling and system architecting. Communications of the ACM, 46(10):63-65. [doi:10. 1145/944217.944240]

Dourish, P., 2004. What we talk about when we talk about context. Personal and Ubiquitous Computing, 8(1): 19-30. [doi:10.1007/s00779-003-0253-8]

Ehrlenspiel, K., 1994. Theory of technical systems. Journal of Engineering Design, 5(2):117-128. [doi:10.1080/ 09544829408907877]
Eze, T., Anthony, R.J., Walshaw, C., et al., 2011. The challenge of validation for autonomic and self-managing systems. Proceedings of the Seventh International Conference on Autonomic and Autonomous Systems, p.128-133.

Ezell, B.C., Crowther, K.G., 2007. Philosophical issues and their implications for the systems architect. Foundations of Science, 12(3):269-276. [doi:10.1007/s10699-0079108-5]

Farber, D.J., 2002. Predicting the unpredictable: future directions in internetworking and their implications. IEEE Communications Magazine, 40(7):67-71. [doi:10.1109/ MCOM.2002.1018009]

Feiler, P.H., 2009. Challenges in validating safety-critical embedded systems. SAE Technical Paper, No. 2009-01 -3284 .

Ferretti, G., Magnani, G., Rocco, P., 2004. Virtual prototyping of mechatronic systems. Annual Reviews in Control, 28(2):193-206. [doi:10.1016/j.arcontrol.2004.02.002]

Finnveden, G., Moberg, Å., 2005. Environmental systems analysis tools - an overview. Journal of Cleaner Production, 13(12):1165-1173. [doi:10.1016/j.jclepro.2004.06. 004]

Flood, R.L., 1989. Six scenarios for the future of systems “problem solving”. Systems Practice, 2(1):75-99. [doi:10. 1007/BF01061618]

Flood, R.L., Carson, E.R., 1993. Dealing with Complexity: an Introduction to the Theory and Application of Systems Science. Plenum Press, New York. [doi:10.1007/978-14757-2235-2]

Forester, T., 1992. Megatrends or megamistakes? What ever happened to the information society? The Information Society, 8(3):133-146. [doi:10.1080/01972243.1992. 9960117]

Foster, J., Kay, J., Roe, P., 2001. Teaching complexity and systems thinking to engineers. Management, 3:11.

Gaines, B.R., 1977. System identification, approximation and complexity. International Journal of General System, 3(3):145-174. [doi:10.1080/03081077708934759]

Gish, K.W., Saplin, L., Perel, M., 1999. Human factors issues related to use of vision enhancement systems. Transportation Research Record: Journal of the Transportation Research Board, 1694(1):1-9. [doi:10.3141/1694-01]

Goel, A.K., Rugaber, S., Vattam, S., 2009. Structure, behaviour, and function of complex systems: The structure, behaviour, and function modelling language. Artificial Intelligence for Engineering Design, Analysis and Manufacturing, 23(01):23-35. [doi:10.1017/S0890060409 000080]

Gonçalves, R., Gudwin, R., 1998. Semiotic oriented autonomous intelligent systems engineering. Proceedings of Intelligent Control, IEEE, p.700-705.

Gonzalez, A.J., Barr, V., 2000. Validation and verification of intelligent systems-What are they and how are they different? Journal of Experimental \& Theoretical Artificial Intelligence, 12(4):407-420. [doi:10.1080/095281300 454793]

Gössler, G., Graf, S., Majster-Cederbaum, M., et al., 2007. An approach to modelling and verification of component 
based systems. Proceedings of Theory and Practice of Computer Science, Springer, Berlin, p.295-308.

Goubault, E., Martel, M., Putot, S., 2006. Some future challenges in the validation of control systems. European Congress on Embedded Real Time Software, p.1-11.

Grabowski, F., 2013. Nonextensive model of self-organizing systems. Complexity, 18(5):28-36. [doi:10.1002/cplx. 21438]

Griffiths, M.D., Parke, J., 2002. The social impact of internet gambling. Social Science Computer Review, 20(3): 312-320. [doi:10.1177/08939302020003008]

Grippa, F., Secundo, G., 2009. Web 2.0 project-based learning in higher education: some preliminary evidence. International Journal of Web Based Communities, 5(4): 543-561. [doi:10.1504/IJWBC.2009.028089]

Grobshtein, Y., Perelman, V., Safra, E., et al., 2007. Systems modelling languages: OPM versus SysML. Proceedings of the International Conference on Systems Engineering and Modelling, IEEE, p.102-109.

Haimes, Y.Y., 2012. Modelling complex systems of systems with phantom system models. Systems Engineering, 15(3):333-346. [doi:10.1002/sys.21205]

Hall, A.D., 1962. A Methodology for Systems Engineering. Van Nostrand, New Jersey.

Harel, D., Rumpe, B., 2004. Modelling languages: syntax, semantics and all that stuff. IEEE Software, p.1-28.

Harms, W., 2011. Evolutionary games and the modelling of complex systems. Philosophy of Complex Systems, 10: 163. [doi:10.1016/B978-0-444-52076-0.50005-5]

Harrison, R., West, A.A., 2000. Component based paradigm for the design and implementation of control systems in electronics manufacturing machinery. Journal of Electronics Manufacturing, $\mathbf{1 0}(01): 1-17$. [doi:10.1142/ S0960313100000022]

Heerink, L., Brinksma, E., 1995. Validation in context. Proceedings of 15th IFIP WG6.1 International Symposium on Protocol Specification, Testing, and Verification, Chapman \& Hall, p. 221-236.

Heikal, M.R., Peeling, K.A., 1991. An integrating role for the microcomputer in engineering education. Proceedings of the Institution of Mechanical Engineers, Part A: Journal of Power and Energy, 205(1):37-41.

Hewitt, C., 1985. The challenge of open systems: current logic programming methods may be insufficient for developing the intelligent systems of the future. Byte, 10(4):223-242.

Hirschheim, R., Klein, H.K., 1989. Four paradigms of information systems development. Communications of the ACM, 32(10):1199-1216. [doi:10.1145/67933.67937]

Hofkirchner, W., Schafranek, M., 2011. General system theory: philosophy of complexity, chaos, and non-linearity. In: Hooker, C. (Ed.), Handbook of the Philosophy of Science. Elsevier, UK, 10:177-194.

Holland, J.H., 2006. Studying complex adaptive systems. Journal of Systems Science and Complexity, 19(1):1-8. [doi:10.1007/s11424-006-0001-z]

Holloway, L.E., Krogh, B.H., Giua, A., 1997. A survey of Petri net methods for controlled discrete event systems. Discrete Event Dynamic Systems, 7(2):151-190. [doi:10.

\section{3/A:1008271916548]}

Hooker, C., 2011. Introduction to philosophy of complex systems. Part A: towards framing philosophy of complex systems. In: Philosophy of Complex Systems. Elsevier, Amsterdam, p.3-92. [doi:10.1016/B978-0-444-520760.50001-8]

Horváth, A., Matthews, H.S., 2004. Advancing sustainable development of infrastructure systems. Journal of Infrastructure Systems, 10(3):77-78. [doi:10.1061/(ASCE) 1076-0342(2004)10:3(77)]

Horváth, I., Pourtalebi, S., 2015. Fundamentals of a mereooperandi theory to support transdisciplinary modelling and co-design of cyber-physical systems. Proceedings of the ASME 2015 International Design Engineering Technical Conferences, Boston, MA, USA, p.1-12.

Horváth, I., Gerritsen, B., Rusák, Z., 2010. A new look at virtual engineering. Proceedings of Mechanical Engineering Conference, Budapest, p.25-26.

Hoschka, P., 1996. Computers as Assistants: a New Generation of Support Systems. Lawrence Erlbaum Associates, Mahwah, NJ, USA.

Hubka, V., 1973. Theorie der Maschinensysteme: Grundlagen einer Wissenschaftlichen Konstruktionslehre. Springer, Berlin (in German).

Hubka, V., Eder, W.E., 1988. Theory of Technical Systems: a Total Concept Theory for Engineering Design. SpringerVerlag, Berlin and New York, p.1-291. [doi:10.1007/ 978-3-642-52121-8]

Hubka, V., Eder, W.E., 2002. Theory of Technical Systems and Engineering Design Synthesis. Springer, London, p.49-66. [doi:10.1007/978-1-4471-3717-7_4]

Iivari, J., Maansaari, J., 1998. The usage of systems development methods: are we stuck to old practices? Information and Software Technology, 40(9):501-510. [doi:10.1016/ S0950-5849(98)00077-9]

INCOSE (International Council on Systems Engineering), 2007. What is systems engineering? INCOSE, San Diego, USA. Available from www.incose.org/practice/ whatissystemseng.aspx.

Itoh, I., 1991. Degradation of material properties in the space environment. Corrosion Engineering (Zairyo-toKankyo), 40(3):208-213 (in Japanese). [doi:10.3323/ jcorr1991.40.208]

Jackson, M.C., 1990. Beyond a system of systems methodologies. Journal of the Operational Research Society, 41(8):657-668. [doi:10.2307/2583472]

Jackson, M.C., Keys, P., 1984. Towards a system of systems methodologies. The Journal of the Operational Research Society, 35(6):473-486. [doi:10.2307/2581795]

Jain, L.C., Jain, R.K., 1997. Hybrid Intelligent Engineering Systems. World Scientific, New York.

Jamshidi, M., 1996. Large-scale systems: modelling, control, and fuzzy logic. In: Series on Environmental and Intelligent Manufacturing Systems. Prentice Hall, p.8.

Janocha, H., 2007. Adaptronics and Smart Structures. SpringerVerlag, Berlin. [doi:10.1007/978-3-540-71967-0]

Jha, A.R., 2012. Next-generation Batteries and Fuel Cells for Commercial, Military, and Space Applications. CRC 
Press, Boca Raton, USA.

Jogalekar, P., Woodside, M., 2000. Evaluating the scalability of distributed systems. IEEE Transactions on Parallel and Distributed Systems, 11(6):589-603. [doi:10.1109/ 71.862209]

Jørgensen, S.E., Patten, B.C., Straškraba, M., 1992. Ecosystems emerging: toward an ecology of complex systems in a complex future. Ecological Modelling, 62(1-3):1-27. [doi:10.1016/0304-3800(92)90080-X]

Kang, I., Heung, Y.Y., Kim, J.H., et al., 2006. Introduction to carbon nanotube and nanofiber smart materials. Composites Part B: Engineering, 37(6):382-394. [doi:10.1016/ j.compositesb.2006.02.011]

Kieras, D.E., 1988. What mental model should be taught: choosing instructional content for complex engineered systems. In: Psotka, J., Massey, L.D., Mutter, S.A. (Eds.), Intelligent Tutoring Systems: Lessons Learned. Lawrence Erlbaum Associates, Inc., Publishers, New Jersey, USA, p.85-111.

Kirschenmann, P.P., 1984. Philosophical evaluations of systems theory. In: Contemporary Marxism. Springer, the Netherlands, p.79-96. [doi:10.1007/978-94-009-6268$26]$

Klir, G.J., 1985. Architecture of Systems Problem Solving. Plenum Press, New York.

Kraut, R., Patterson, M., Lundmark, V., et al., 1998. Internet paradox: a social technology that reduces social involvement and psychological well-being? American Psychologist, 53(9):1017. [doi:10.1037/0003-066X.53.9. 1017]

Kroes, P.A., Franssen, M.P., van de Poel, I., et al., 2006. Treating socio-technical systems as engineering systems: some conceptual problems. Systems Research and Behavioral Science, 23(6):803-814. [doi:10.1002/sres.703]

Kushner, M.P., Song, I.Y., Whang, K.Y., 2001. A comparison of three systems modelling methodologies. Proceedings of High-performance Web Databases, Design, Development, and Deployment Conference, Auerbach Publications, Boston, MA, USA, p.195-212.

Kwiatkowska, M., Norman, G., Parker, D., et al., 2010. Assume-guarantee verification for probabilistic systems. Tools and Algorithms for the Construction and Analysis of Systems, Springer, Berlin, p.23-37. [doi:10.1007/ 978-3-642-12002-2_3]

Leng, J., Lu, H., Liu, Y., et al., 2009. Shape-memory polymers -A class of novel smart materials. MRS Bulletin, 34(11): 848-855. [doi:10.1557/mrs2009.235]

Li, Z., Raskin, V., Ramani, K., 2008. Developing engineering ontology for information retrieval. Journal of Computing and Information Science in Engineering, 8(1):011003. [doi:10.1115/1.2830851]

Li, Z., Yang, M.C., Ramani, K., 2009. A methodology for engineering ontology acquisition and validation. Artificial Intelligence for Engineering Design, Analysis and Manufacturing, 23(01):37-51. [doi:10.1017/S0890060 409000092]

Liker, J.K., Majchrzak, A., Choi, T., 1993. Impacts of programmable manufacturing technology: a review of recent studies and contingency formulation. Journal of Engineering and Technology Management, 10(3):229-264. [doi:10.1016/0923-4748(93)90070-Y]

Liserre, M., Sauter, T., Hung, J.Y., 2010. Future energy systems: integrating renewable energy sources into the smart power grid through industrial electronics. IEEE Industrial Electronics Magazine, p.18-37.

Litan, R.E., Rivlin, A.M., 2001. Projecting the economic impact of the Internet. American Economic Review Papers and Proceedings, 91(2):313-317. [doi:10.1257/aer.91.2. 313]

Liu, H.B., Gu, G.C., Zhang, G.Y., 2003. Research on classification of intelligent robot architectures. Journal of Harbin Engineering University, 24(6):664-668 (in Chinese).

Lueth, T.C., Laengle, T., Herzog, G., et al., 1994. KANTRAHuman-machine interaction for intelligent robots using natural language. Proceedings of the 3rd International Workshop on Robot and Human Communication, IEEE, Nagoya, p.106-111.

Luo, R.C., Su, K.L., Shen, S.H., et al., 2003. Networked intelligent robots through the Internet: issues and opportunities. Proceedings of the IEEE, 91(3):371-382. [doi:10.1109/JPROC.2003.809198]

Madni, A.M., 2010. Integrating humans with software and systems: technical challenges and a research agenda. Systems Engineering, 13(3):232-245.

Maier, M.W., 1996. Systems architecting: an emergent discipline. Proceedings of the Aerospace Applications Conference, IEEE, 3:231-245.

Malhotra, N.K., Kim, S.S., Agarwal, J., 2004. Internet users' information privacy concerns: the construct, the scale, and a causal model. Information Systems Research, 15(4):336-355. [doi:10.1287/isre.1040.0032]

Marchal, J.H., 1975. On the concept of a system. Philosophy of Science, 42(4):448-468. [doi:10.1086/288663]

Mayer, F., 2008. Social impact of automation trends and issues: a human centered systems engineering perspective. Proceedings of the 17th World Congress of the International Federation of Automatic Control, Seoul, Korea, p.6-11.

Mayne, A.J., 1998. Cybernetics for the 21st century. Proceedings of the 15th International Congress on Cybernetics, IAC, Namur, p.934-939.

McGinn, R.E., 1991. Science, Technology, and Society. Prentice Hall, Englewood Cliffs, USA, p.244-248.

Mendes, O., Abran, A., 2005. Issues in the development of an ontology for an emerging engineering discipline. Proceedings of the First Workshop on Ontology, Conceptualizations and Epistemology for Software and Systems Engineering, Henares, Spain, p.139-144.

Mesarović, M.D., 1971. Mathematical theory of general systems. Proceedings of the Symposium on Differential Equations and Dynamical Systems, Springer, p.14-15. [doi:10.1007/BFb0070125]

Meyer, M.H., Curley, K.F., 1991. An applied framework for classifying the complexity of knowledge-based systems. MIS Quarterly, 15(4):455-472. [doi:10.2307/249450] 
Mina, A.A., Braha, D., Bar-Yam, Y., 2006. Complex engineered systems: a new paradigm. In: Complex Engineered Systems. Springer, Berlin, p.1-21. [doi:10. 1007/3-540-32834-3 1]

Minai, A., Perdoor, M., Byadarhaly, K.V., et al., 2010. A synergistic view of autonomous cognitive systems. Proceedings of the International Joint Conference on Neural Networks, IEEE, p.1-8.

Minar, N., 2002. Distributed systems topologies: Part 2. O'Reilly Open P2P, p.1-7.

Mitchell, C.M., Sundstrom, G.A., 1997. Human interaction with complex systems: design issues and research approaches. IEEE Transactions on Systems, Man, and Cybernetics Part A: Systems and Humans, 27(3):265-273.

Mitsch, W.J., 1996. Ecological engineering: a new paradigm for engineers and ecologists. In: Engineering within Ecological Constraints. National Academy Press, Washington DC, p.111-128.

Möbus, C., 1996. Towards an epistemology of intelligent design and modelling environments: the hypothesis testing approach. Proceedings of the European Conference on Artificial Intelligence in Education, Lisbon, Portugal, p.52-58.

Moon, B.M., Wei, S., Cox, D.A., 2004. Cognitive impact metrics: applying macrocognition during the design of complex cognitive systems. Proceedings of the Human Factors and Ergonomics Society Annual Meeting, SAGE Publications, 48(3):473-477. [doi:10.1177/15419312040 4800342]

Mordinyi, R., Moser, T., Winkler, D., et al., 2012. Navigating between tools in heterogeneous automation systems engineering landscapes. Proceedings of the 38th Annual Conference on Industrial Electronics Society, IEEE, p.6178-6184.

M'Pherson, P.K., 1980. Systems engineering: an approach to whole-system design. Radio and Electronic Engineer, 50(11-12):545-558. [doi:10.1049/ree.1980.0081]

Muller, G., 2013. Systems engineering research methods. Procedia Computer Science, 16:1092-1101. [doi:10. 1016/j.procs.2013.01.115]

Nersessian, N.J., 2006. Model-based reasoning in distributed cognitive systems. Philosophy of Science, 73(5):699-709. [doi:10.1086/518771]

Neumann, D., 2007. Adaptronics: a concept for the development of adaptive and multifunctional structures. In: Adaptronics and Smart Structures. Springer, Berlin, p.1-8.

$\mathrm{Ng}, \mathrm{C} ., 2004$. Findings from a web based survey of degree programs in engineering systems. Proceedings of the Engineering Systems Symposium, p.1-26.

Niehaves, B., 2007. On epistemological pluralism in design science. Scandinavian Journal of Information Systems, 19(2): Article 7.

Nijholt, A., Tan, D., 2008. Brain-computer interfacing for intelligent systems. Intelligent Systems, IEEE, 23(3): 72-79. [doi:10.1109/MIS.2008.41]

Norman, K.L., 1997. Cognitive impact of graphical user interfaces. Cognitive Technology, 2:22-30.

Ny, H., MacDonald, J.P., Broman, G., et al., 2006. Sustaina- bility constraints as system boundaries: an approach to making life-cycle management strategic. Journal of Industrial Ecology, 10(1-2):61-77.

O’Donnell, D., Henriksen, L.B., 2002. Philosophical foundations for a critical evaluation of the social impact of ICT. Journal of Information Technology, 17(2):89-99. [doi:10. 1080/02683960210145968]

Oliga, J.C., 1988. Methodological foundations of systems methodologies. Systems Practice, 1(1):87-112. [doi:10. 1007/BF01059890]

Ossimitz, G., 2000. Entwicklung Systemischen Denkens. Profil Verlag, München (in German).

Ottens, M.M., 2007. A conceptual representation of complex systems. Proceedings of the Conference on System Engineering Research, Hoboken, NJ, USA, p.1-11.

Perrolle, J.A., 1988. The social impact of computing: ideological themes and research issues. Social Science Computer Review, 6(4):469-480. [doi:10.1177/08944393 8800600402]

Persson, M., Törngren, M., Qamar, A., et al., 2013. A characterization of integrated multi-view modelling in the context of embedded and cyber-physical systems. Proceedings of the Eleventh ACM International Conference on Embedded Software, IEEE Press, p.10.

Prensky, M., 2003. Digital game-based learning. Computers in Entertainment, 1(1):21-21. [doi:10.1145/950566.950596]

Priya, S., Inman, D.J. (Eds.), 2009. Energy Harvesting Technologies, Vol. 21. Springer, New York. [doi:10.1007/ 978-0-387-76464-1]

Ramesh, B., Tiwana, A., 1999. Supporting collaborative process knowledge management in new product development teams. Decision Support Systems, 27(1-2):213-235. [doi:10.1016/S0167-9236(99)00045-7]

Ranganathan, A., Campbell, R.H., 2007. What is the complexity of a distributed computing system? Complexity, 12(6):37-45. [doi:10.1002/cplx.20189]

Ray, W.A., 2005. On being cybernetic. Kybernetes, 34(3/4): 360-364. [doi:10.1108/03684920510581530]

Rennings, K., 2000. Redefining innovation-eco-innovation research and the contribution from ecological economics. Ecological Economics, 32(2):319-332. [doi:10.1016/ S0921-8009(99)00112-3]

Rhodes, D., Hastings, D., 2004. The case for evolving systems engineering as a field within engineering systems. Proceedings of the 1st MIT Engineering Symposium, p.1-9.

Roe, E., Schulman, P., van Eeten, M., et al., 2005. High-reliability bandwidth management in large technical systems: findings and implications of two case studies. Journal of Public Administration Research and Theory, 15(2):263-280. [doi:10.1093/jopart/mui015]

Romano, A., Secundo, G., 2009. Dynamic Learning Networks: Models and Cases in Action. Springer Science \& Business Media, New York. [doi:10.1007/978-1-4419-0251 -1]

Roth, K.H., 1981. Foundation of methodical procedures in design. Design Studies, 2(2):107-115. [doi:10.1016/0142694X(81)90007-7]

Sainter, P., Oldham, K., Larkin, A., et al., 2000. Product 
knowledge management within knowledge-based engineering systems. Proceedings of the Design Engineering Technical Conference, ASME, Baltimore, p.1-10.

Salthe, S.N., 2012. Hierarchical structures. Axiomathes, 22(3): 355-383. [doi:10.1007/s10516-012-9185-0]

Salthe, S.N., Matsuno, K., 1995. Self-organization in hierarchical systems. Journal of Social and Evolutionary Systems, 18(4):327-338. [doi:10.1016/1061-7361(95)90022 $-5]$

Sapuan, S.M., 2001. A knowledge-based system for materials selection in mechanical engineering design. Materials \& Design, 22(8):687-695. [doi:10.1016/S0261-3069(00) 00108-4]

Sarder, B., Ferreira, S., 2007. Developing systems engineering ontologies. Proceedings of the IEEE International Conference on System of Systems Engineering, San Antonio, TX, USA, p.1-6.

Sarnikar, S., Deokar, A., 2010. Knowledge management systems for knowledge-intensive processes: design approach and an illustrative example. Proceedings of the 43rd Hawaii International Conference on System Sciences, IEEE, p.1-10.

Schaf, F.M., Pereira, C.E., Assis, A.C., et al., 2007. Collaborative learning environment using distributed mixed reality experiment for teaching mechatronics. Proceedings of the 8th IFAC Symposium on Cost Oriented Automation, 8(1):120-125.

Schmid, K., Verlage, M., 2002. The economic impact of product line adoption and evolution. IEEE Software, 19(4):50-57. [doi:10.1109/MS.2002.1020287]

Schulman, P., Roe, E., Eeten, M.V., et al., 2004. High reliability and the management of critical infrastructures. Journal of Contingencies and Crisis Management, 12(1): 14-28. [doi:10.1111/j.0966-0879.2004.01201003.x]

Sengupta, S.S., Ackoff, R.L., 1965. Systems theory from an operations research point of view. IEEE Transaction on Systems Science and Cybernetics, 1(1):9-13. [doi:10. 1109/TSSC.1965.300053]

Sheard, S., 2006. Is systems engineering for "systems of systems" really any different? INSIGHT, 9(1):19-20. [doi:10. 1002/inst.20069119]

Shibata, N., Kajikawa, Y., Takeda, Y., et al., 2008. Detecting emerging research fronts based on topological measures in citation networks of scientific publications. Technovation, 28(11):758-775. [doi:10.1016/j.technovation.2008. 03.009]

Sicilia, M.A., 2007. Ontology of systems and software engineering. Advanced Engineering Informatics, 21(2):117118. [doi:10.1016/j.aei.2006.11.005]

Sinha, R., Paredis, C.J., Liang, V.C., et al., 2001. Modelling and simulation methods for design of engineering systems. Journal of Computing and Information Science in Engineering, 1(1):84-91. [doi:10.1115/1.1344877]

Smith, N.J., Sage, A.P., 1973. An introduction to hierarchical systems theory. Computers \& Electrical Engineering, 1(1):55-71. [doi:10.1016/0045-7906(73)90027-X]

Smuts, J.C., 1926. Holism and Evolution. MacMillan, London. Stylios, C.D., Christova, N., Groumpos, P.P., 1999. Using soft computing methodologies for multistage supervisory control of complex systems. Proceedings of the 7th Mediterranean Conference on Control and Automation, Haifa, p.2274-2284.

Subrahmanyam, K., Kraut, R.E., Greenfield, P.M., et al., 2000. The impact of home computer use on children's activities and development. Children and Computer Technology, 10(2):123-144.

Sutherland, J.W., 1978. System science and societal integrity. IEEE Transactions on Systems, Man, and Cybernetics, 8(12):837-848. [doi:10.1109/TSMC.1978.4309883]

Sviokla, J.J., 1990. An examination of the impact of expert systems on the firm: the case of XCON. MIS Quarterly, 14(2):127-141. [doi:10.2307/248770]

Ta'eed, O., 1986. Teleology of engineering research. European Journal of Engineering Education, 11(4):389-411.

Tani, J., Takagi, T., Qiu, J., 1998. Intelligent material systems: application of functional materials. Applied Mechanics Reviews, 51(8):505-521. [doi:10.1115/1.3099019]

Thurman, D.A., Mitchell, C.M., 1994. A methodology for the design of interactive monitoring interfaces. International Conference on Systems, Man, and Cybernetics, San Antonio, TX, USA, 2:1739-1744. [doi:10.1109/ICSMC. 1994.400100]

Thurman, D.A., Brann, D.M., Mitchell, C.M., 1997. An architecture to support incremental automation of complex systems. International Conference on Systems, Man, and Cybernetics, IEEE, Orlando, FL, USA, 2:1174-1179.

Tipsuwan, Y., Chow, M.Y., 2003. Control methodologies in networked control systems. Control Engineering Practice, 11(10):1099-1111. [doi:10.1016/S0967-0661(03) 00036-4]

Torresen, J., 2004. An evolvable hardware tutorial. In: Field Programmable Logic and Application. Springer, Berlin, p.821-830. [doi:10.1007/978-3-540-30117-2_83]

Troncale, L., 2009. Revisited: the future of general systems research: update on obstacles, potentials, case studies. Systems Research and Behavioral Science, 26(5): 553-561. [doi:10.1002/sres.997]

Ulrich, W., 1988. Systems thinking, systems practice, and practical philosophy: a program of research. Systems Practice, 1(2):137-163. [doi:10.1007/BF01059855]

van Dam, A., Becker, S., Simpson, R.M., 2007. Nextgeneration educational software: why we need it \& a research agenda for getting it. ACM SIGGRAPH 2007 Courses, ACM, p.32. [doi:10.1145/1281500.1281543]

van de Laar, P., Douglas, A.U., America, P., 2011. Researching evolvability. Views on Evolvability of Embedded Systems, Springer, the Netherlands, p.1-20. [doi:10.1007/ 978-90-481-9849-8]

van der Hoek, W., Wooldridge, M., 2008. Multi-agent systems. Foundations of Artificial Intelligence, 3:887-928. [doi:10.1016/S1574-6526(07)03024-6]

Varaiya, P., 2000. A question about hierarchical systems. In: System Theory. Springer US, New York, p.313-324. [doi:10. 1007/978-1-4615-5223-9_23]

Verhagen, W.J., Curran, R., 2010. Knowledge-based engineering review: conceptual foundations and research 
issues. In: New World Situation: New Directions in Concurrent Engineering. Springer, London, p.267-276.

Verhagen, W.J., Bermell-Garcia, P., van Dijk, R.E., et al., 2012. A critical review of knowledge-based engineering: an identification of research challenges. Advanced Engineering Informatics, 26(1):5-15. [doi:10.1016/j.aei.2011. 06.004]

Vermaas, P.E., Houkes, W., 2006. Technical functions: a drawbridge between the intentional and structural natures of technical artefacts. Studies in History and Philosophy of Science: Part A, 37(1):5-18. [doi:10.1016/j.shpsa. 2005.12.002]

Vincent, J.F., Mann, D.L., 2002. Systematic technology transfer from biology to engineering. Philosophical Transactions of the Royal Society of London, Series A: Mathematical, Physical and Engineering Sciences, 360(1791):159-173.

von Bertalanffy, L., 1950a. An outline of general system theory. The British Journal for the Philosophy of Science, 1(2):134-165. [doi:10.1093/bjps/I.2.134]

von Bertalanffy, L., 1950b. The theory of open systems in physics and biology. Science, 111(2872):23-29. [doi:10. 1126/science.111.2872.23]

Voorhees, B.H., 1983. Axiomatic theory of hierarchical systems. Behavioral Science, 28(1):24-34. [doi:10.1002/ bs.3830280105]

Wang, F.H., Chen, D.Y., 2008. A knowledge integration framework for adaptive learning systems based on semantic web languages. Proceedings of the Eighth International Conference on Advanced Learning Technologies, IEEE, p.64-68. [doi:10.1109/ICALT.2008.217]

Wangler, B., Backlund, A., 2005. Information systems engineering: what is it? Proceedings of the CAiSE Workshops, 2:427-437.

Warfield, J.N., 2003. A proposal for systems science. Systems Research and Behavioral Science, 20(6):507-520. [doi:10.1002/sres.528]

West, A.A., Bowen, B.A., Monfared, R.P., et al., 2000. Userresponsive interface generation for manufacturing systems: a theoretical basis. Proceedings of the Institution of Mechanical Engineers, Part B: Journal of Engineering Manufacture, 214(5):379-392. [doi:10.1243/0954405001 518161]

Whitman, M.E., 2003. Enemy at the gate: threats to information security. Communications of the ACM, 46(8): 91-95. [doi:10.1145/859670.859675]

Wilber, K., 2001. Sex, Ecology, Spirituality: the Spirit of Evolution. Shambhala Publications, USA.

Wimsatt, W.C., 1994. The ontology of complex systems: levels of organization, perspectives, and causal thickets. Canadian Journal of Philosophy, 24(1):207-274.

Winter, M.C., Brown, D.H., Checkland, P.B., 1995. A role for soft systems methodology in information systems development. European Journal of Information Systems, 4(3):130-142. [doi:10.1057/ejis.1995.17]

Wise, J.A., Wise, M.A., 1993. Basic considerations in verification and validation. In: Verification and Validation of
Complex Systems: Human Factors Issues. Springer, Berlin, p.87-95. [doi:10.1007/978-3-662-02933-6_4]

Wolf, C.P., 1983. Social impact assessment: methodological overview. In: Environmental Impact Assessment. Springer, the Netherlands, p.253-279. [doi:10.1007/97894-009-6795-3_13]

Wongthongtham, P., Chang, E., Dillon, T., et al., 2009. Development of a software engineering ontology for multisite software development. IEEE Transactions on Knowledge and Data Engineering, 21(8):1205-1217. [doi:10.1109/TKDE.2008.209]

Wood-Harper, A.T., Fitzgerald, G., 1982. A taxonomy of current approaches to systems analysis. The Computer Journal, 25(1):12-16. [doi:10.1093/comjnl/25.1.12]

Wynekoop, J.L., Russo, N.L., 1997. Studying system development methodologies: an examination of research methods. Information Systems Journal, 7(1):47-65. [doi:10.1046/j.1365-2575.1997.00004.x]

Yager, R.R., 1994. Aggregation operators and fuzzy systems modelling. Fuzzy Sets and Systems, 67(2):129-145. [doi:10.1016/0165-0114(94)90082-5]

Yang, P., Tarascon, J.M., 2012. Towards systems materials engineering. Nature Materials, 11(7):560-563. [doi:10. 1038/nmat3367]

Yoshida, T., Kuroda, H., Nishigaito, T., 2004. Adaptive driverassistance systems. Hitachi Review, 53(4):213.

Zhang, G., Li, Y., 2010. Agent-based modelling and simulation for open complex systems. Proceedings of the 2nd International Asia Conference on Informatics in Control, Automation and Robotics, IEEE, 1:504-507.

Zhang, Z., Jia, L., Chai, Y., et al., 2008. On conceptual and methodological issues in control of complex systems. Proceedings of the International Conference on Systems, Man and Cybernetics, Singapore, p.3576-3581.

\section{中文概要}

\section{题 目：复杂技术系统中基础研究的初步分类}

目 的: 对于复杂技术系统, 给出不同研究领域的初步分 类, 并找出一些研究关注的问题。

创新点: 提出了一种推理方法, 将复杂技术系统的研究领 域分为三类。

方 法: 1. 对相关的学术刊物进行直觉探索; 2. 对领域 和子领域研究给出基于证据的分类规范; 3. 对 基于相关学术刊物的控制给出的分类进行提炼 与验证。

结 论: 复杂技术系统的研究领域分为三类, 分别为: (1) 智能化类, 包括哲学、本体和认识论; (2) 实 现类，包括方法论和复杂技术系统的创建; (3) 影响类, 包括表现和价值学。

关键词: 基础研究; 复杂技术系统; 初步分类; 研究范畴 与领域 